Institute of Animal Breeding and Genetics

Georg-August-University of Göttingen

\title{
Genetic Parameters for Productive and Reproductive Traits of Sows in Multiplier Farms
}

\author{
Doctoral Dissertation \\ submitted for the degree of Doctor of Agricultural Sciences \\ of the Faculty of Agricultural Sciences \\ Georg-August-University of Göttingen (Germany)
}

\author{
by \\ Hyung-Joo Kim \\ born in Seoul/Korea
}

Göttingen, July 2001

supported by the programme "Nachwuchswissenschaftler aus außereuropäischen Ländern nach Niedersachsen" of the Niedersächsisches Ministerium für Wissenschaft und Kultur 
D7

$1^{\text {st }}$ examiner: $\quad$ Prof. Dr. P. Glodek

$2^{\text {nd }}$ examiner: $\quad$ Prof. Dr. H. Brandt

Date of oral examination: $12^{\text {th }}$ July 2001 
Sun-Young, Joon-Yong, Joon-Hee and My Parents 



\section{Table of Contents}

Page

1. Introduction 1

2.

2. 1. Information from sow management programmes 3

2.1.1. Utilisation of data from sow management programmes 3

2. 1.2. Sow management programmes data from multiplier farms 4

2. 2. Relationship between productive and reproductive traits 5

2. 3. Genetic parameters for reproductive traits 6

2. 3. 1. Heritabilities for litter traits 6

2. 3. 2. Heritabilities for calculated intervals 9

2. 3.3. Genetic correlations between reproductive traits 10

3. Material and Methods 13

$\begin{array}{lll}\text { 3. 1. Data } & 13\end{array}$

3. 1. 1. Performance test records 13

3. 1. 1. 1. Characteristics of the performance test records 13

3. 1. 2. Litter records 15

3. 1. 2. 1. Characteristics of the litter records 17 
3. 2. Statistical analysis 20

3. 2. 1. The analysed data material 20

3. 2. 2. Models 21

3. 2. 2. 1. Model for litter size in the birth litter on productive traits 21

3. 2. 2. 2. Model for the tests of fixed effects on litter traits 21

3. 2. 2. 3. Models for estimation of parameters 22

4. Results $\quad 25$

4. 1. The effect of litter size in the birth litter on parameters for backfat thickness and average daily gain of young sows tested 25

4. 2. Significance test for litter traits

4. 3. Estimation of variance components within each parity 31

4. 3. 1. Analyses for the litter traits 31

4. 3. 2. Analyses for the calculated intervals 33

4. 4. Estimation of variance components between parities 36

4. 4. 1. Analyses for the litter traits 36

4. 4. 2. Analyses for the calculated intervals 38

4. 5. Estimation of variance components using a repeatability model $\quad 40$ 
4. 6. Estimation of variance components using the models including productive traits $\quad 42$

4. 6. 1. Litter traits, backfat and daily gain 42

4. 6. 2. Calculated intervals 44

5. Discussion 47

5. 1. The effect of litter size in the birth litter on daily gain and backfat thickness of young sows tested $\quad 47$

5. 2. The fixed effects upon reproductive traits 47

5. 3. Estimates of variance components for reproductive traits 49

5. 4. Genetic correlations among reproductive traits 53

5. 5. Genetic correlations between reproductive and productive traits $\quad 55$

5. 6. Conclusions $\quad 56$

$\begin{array}{lll}\text { 6. Summary } & 57\end{array}$

7. Zusammenfassung $\quad 59$

8. $\quad$ References 61 



\section{$\underline{\text { List of Tables }}$}

Page

2.1. Accuracy of traits recorded in sow management programmes …........................ 3

2.2. Estimates of heritability for litter traits from the literature ………………......... 8

3.1. Reduction of performance test records because of biological limits and pedigree

3.2. Distribution of observations in edited performance test records

3.3. Mean values (Mean), standard deviations (SD), minimum values (Min) and maximum values (Max) for the traits $(n=91,909)$

3.4. Reduction of litter records because of biological limits and pedigree ……...

3.5 Distribution of litters in edited litter records

3.6. Number of observations (N), mean values (Mean), standard deviations (SD) minimum values (Min) and maximum values (Max) for the traits within parity

3.7. Distribution of litters in analysed data material

3.8. Distribution of sows over farm, sire and dam

4.1. Estimates of variance and covariance components for backfat thickness and daily gain from the four different models

4.2. Estimates of heritabilities, variance ratios and correlations for backfat thickness and daily gain from the four different models (standard error in brackets)

4.3. Differences in estimated breeding values for daily gain between models $(n=85,664)$

4.4. Significance of effects on the litter traits

4.5. Estimated regression coefficients for the covariates upon litter traits (standard error in brackets) 
4.6. Least square means of litter traits for the parity (standard error in brackets)

4.7. Estimates of additive genetic variance $\left(1^{\text {st }}\right.$ line on the diagonal), residual variance $\left(2^{\text {nd }}\right.$ line on the diagonal), genetic covariance (above the diagonal) and residual covariance (below the diagonal) components for litter traits within parity using a multiple-trait animal model (model 2)

4.8. Estimates of heritabilities (on the diagonal), genetic (above the diagonal) and residual correlations (below the diagonal) for litter traits within parity using a multiple-trait animal model (model 2, standard error in brackets)

4.9. Estimates of additive genetic variance ( $1^{\text {st }}$ line on the diagonal), residual variance $\left(2^{\text {nd }}\right.$ line on the diagonal), genetic covariance (above the diagonal) and residual covariance (below the diagonal) components for litter size and intervals within second parity using a multiple-trait animal model (model 3)

4.10. Estimates of additive genetic variance $\left(1^{\text {st }}\right.$ line on the diagonal), residual variance $\left(2^{\text {nd }}\right.$ line on the diagonal), genetic covariance (above the diagonal) and residual covariance (below the diagonal) components for litter size and intervals within third parity using a multiple-trait animal model (model 3)

4.11. Estimates of heritabilities (on the diagonal), genetic (above the diagonal) and residual correlations (below the diagonal) for litter size and intervals within second parity using a multiple-trait animal model (model 3, standard error in brackets)

4.12. Estimates of heritabilities (on the diagonal), genetic (above the diagonal) and residual correlations (below the diagonal) for litter size and intervals within third parity using a multiple-trait animal model (model 3, standard error in brackets)

4.13. Estimates of additive genetic variance ( $1^{\text {st }}$ line on the diagonal), residual variance $\left(2^{\text {nd }}\right.$ line on the diagonal), genetic covariance (above the diagonal) and residual covariance (below the diagonal) components for litter traits between parities using a multiple-trait animal model (model 2) 
4.14. Estimates of heritabilities (on the diagonal), genetic (above the diagonal) and residual correlations (below the diagonal) for litter traits between parities using a multiple-trait animal model (model 2, standard error in brackets)

4.15. Estimates of additive genetic variance $\left(1^{\text {st }}\right.$ line on the diagonal), residual variance $\left(2^{\text {nd }}\right.$ line on the diagonal), genetic covariance (above the diagonal) and residual covariance (below the diagonal) components for age at first farrowing and farrowing intervals using a multiple-trait animal model (model 3)

4.16. Estimates of additive genetic variance $\left(1^{\text {st }}\right.$ line on the diagonal $)$, residual variance $\left(2^{\text {nd }}\right.$ line on the diagonal), genetic covariance (above the diagonal) and residual covariance (below the diagonal) components for weaning to conception intervals using a multiple-traits animal model (model 3)

4.17. Estimates of heritabilities (on the diagonal), genetic (above the diagonal) and residual correlations (below the diagonal) for age at first farrowing and farrowing intervals using a multiple-trait animal model (model 3, standard error in brackets)

4.18. Estimates of heritabilities (on the diagonal), genetic (above the diagonal) and residual correlations (below the diagonal) for weaning to conception intervals using a multiple-trait animal model (model 3, standard error in brackets)

4.19. Estimates of additive genetic $\left(\mathrm{V}_{\mathrm{A}}\right)$, permanent environmental $\left(\mathrm{V}_{\mathrm{PE}}\right)$ and residual $\left(\mathrm{V}_{\mathrm{E}}\right)$ variance (on the diagonal) and covariance (above the diagonal) components for litter traits using a repeatability model (model 4) ........

4.20. Estimates of heritabilities ( $1^{\text {st }}$ line on the diagonal), repeatabilities $\left(2^{\text {nd }}\right.$ line on the diagonal), genetic ( $1^{\text {st }}$ line above the diagonal), permanent environmental ( $2^{\text {nd }}$ line above the diagonal) and residual correlations (below the diagonal) for litter traits using a repeatability animal model (model 4, standard error in brackets)

4.21. Estimates of additive genetic variance $\left(1^{\text {st }}\right.$ line on the diagonal $)$, residual variance $\left(2^{\text {nd }}\right.$ line on the diagonal), genetic covariance (above the diagonal) and residual covariance (below the diagonal) components for litter traits, backfat thickness and daily gain using a multiple-trait animal model 
4.22. Estimates of heritabilities (on the diagonal), genetic correlations (above the diagonal), and residual correlations (below the diagonal) for litter traits, backfat thickness and daily gain using a multiple-trait animal model (standard error in brackets)

4.23. Estimates of additive genetic ( $1^{\text {st }}$ line on the diagonal), residual variance ( $2^{\text {nd }}$ line on the diagonal), genetic covariance (above the diagonal) and residual covariance (below the diagonal) components for age at first farrowing, farrowing intervals, backfat thickness and daily gain using a multiple-trait animal model

4.24. Estimates of additive genetic ( $1^{\text {st }}$ line on the diagonal), residual variance $\left(2^{\text {nd }}\right.$ line on the diagonal), genetic covariance (above the diagonal) and residual variance (below the diagonal) components for weaning to conception intervals, backfat thickness and daily gain using a multipletrait animal model

4.25. Estimates of heritabilities (on the diagonal), genetic correlations (above the diagonal) and residual correlations (below the diagonal) for age at first farrowing, farrowing intervals, backfat thickness and daily gain using a multiple-trait animal model (standard error in brackets)

4.26. Estimates of heritabilities (on the diagonal), genetic correlations (above the diagonal) and residual correlations (below the diagonal) for weaning to conception intervals, backfat thickness and daily gain using a multipletrait animal model (standard error in brackets) 


\section{$\underline{\text { List of Figures }}$}

Page

2.1. Breeding structure and data flow within the BHZP breeding programme 4

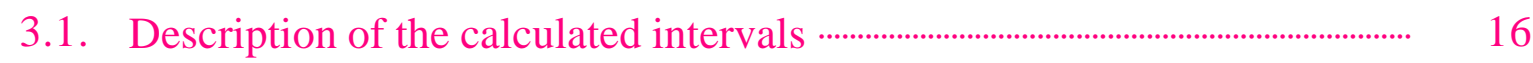

4.1. Effect of litter size in the birth litter on least square means of backfat and daily gain of young sows tested 



\section{$\underline{\text { Abbreviations }}$}

AFF age at first farrowing

AFM age at first mating

BHZP Bundeshybridzuchtprogramm

BLUP best linear unbiased prediction

FI farrowing interval

GL gestation length

GLM general linear model

LSM least square mean

NPBA number of piglets born alive

NPBD number of piglets born dead

NPBT number of piglets born in total

NPW number of piglets weaned

REML restricted maximum likelihood

SD standard deviation

SP suckling period

WCI weaning to conception interval 



\section{Introduction}

Genetic improvement of reproductive performance is one of the most important breeding goals in pigs. Reproductive performance is the major component of sow productivity, and is recognised as a key factor affecting the efficiency and economy of the pig industry for both breeding-herds and commercial producers. Reproductive performance is expected to have a potential for remarkable improvement, due to the introduction of modern statistical methods (e.g. the BLUP animal model) for genetic evaluation (Glodek, 1999). In recent years, intensive selection has been started in dam populations for litter size, achieving variable progress. Litter size has increased genetically by about 1.5 pigs per litter since 1992, when the trait was included in the breeding index in the Netherlands (NCPB, 1997). In Germany, genetic progress in litter size has been rather low so far. It is therefore necessary to improve reproductive performance of dam breeds by systematic breeding efforts. When defining selection objectives for pigs, animal breeders must give attention to sow productive and reproductive traits simultaneously.

For the genetic improvement of increased average daily gain and reduced backfat thickness in pigs, selection has proven to be a successful method in breeding programmes. Industry selection practices in recent years have improved lean meat percentage of carcass and growth. However, decreased reproductive performance as a correlated response of selection for productive traits has been studied. Estimated genetic correlations among productive and reproductive traits are low and sometimes positive or negative (Johansson and Kennedy, 1983; Cleveland et al., 1988; McKay, 1990; Kuhlers and Jungst, 1993; Rydhmer et al., 1995; Tholen et al., 1996b; Adamec and Johnson, 1997; ten Napel and Johnson, 1997). In order to combine both productive and reproductive performances of sows optimally in selection programmes, accurate estimates of variance and covariance components for all traits measured are necessary.

Electronic herd management systems such as "Sauenplaner" provide tools to record these traits accurately under production conditions. Whole-herd, on-farm testing of pigs is becoming more common. Best linear unbiased prediction (BLUP) of breeding values using animal model and restricted maximum likelihood (REML) procedure has been accepted as the method for genetic evaluation of animals and to estimate genetic and environmental parameters. These field records are valuable resources for analysis by animal model method to provide estimates of genetic parameters and to evaluate the effectiveness of applied breeding programmes. 
Reproductive performance is usually considered as the basis for evaluating the genetic merit of animals in a herd, and usually refers to such phenotypic traits as number of piglets born alive and farrowing interval. As traits like litter size are changed by selection, possible correlated responses with other traits need to be considered. Additive genetic variance for litter size is sufficiently large to indicate that selection for improved litter size using an animal model that makes use of all genetic relationships in the data would be successful. Although heritability of reproductive performance is low, use of relatives' records in selection can theoretically result in sizeable gains. Additionally, accurate estimates of genetic parameters will increase the accuracy of estimated breeding value, genetic response of selection and optimising breeding schemes.

The objectives of this study are:

- to estimate genetic parameters for reproductive performance along with growth and backfat measures of sows,

- to use them for constructing optimised selection criteria for dam line sows and boars and

- to develop practical procedures for breeding value estimation and selection of sows and boars in dam line. 


\section{Literature Review}

\section{1. Information from sow management programmes}

\section{1. 1. Utilisation of data from sow management programmes}

In sow management programmes, every mating with date, parity number and the identification of sow and boar are recorded, as well as the information about the litter of a successful mating. Henne et al. (1997a, b) and Brandt et al. (1998) suggested alternative procedures for performance tests in the field, using sow management programmes. The accuracy of the data depends on how accurately farmers are following the instructions of different software packages. In these studies litter size, farrowing interval, age at first farrowing and successful mating could be analysed. The quality of possible data from sow management programmes is summarised in table 2.1 .

Table 2.1. Accuracy of traits recorded in sow management programmes (Brandt and Wörner, 1995)

\begin{tabular}{l|c}
\hline \multicolumn{1}{c|}{ Information } & Quality \\
\hline Number of piglets born alive per litter & Good \\
Number of piglets born dead per litter & Average \\
Number of piglets weaned per litter & Good \\
Weaning losses & Good \\
Reason for weaning losses & Poor \\
Number and type of abnormalities per litter & Poor \\
Age at farrowing / farrowing interval & Good \\
Number of matings per litter and sow & Good \\
Percent successful matings per boar & Average \\
\hline
\end{tabular}




\section{1. 2. Sow management programmes data from multiplier farms}

Figure 2.1 shows the flow of information from field records collected in a stratified breeding programme (BHZP) with nucleus and several multiplier herds (Täubert, 1998). Whole-herd, on-farm testing of pigs in breeding herds is becoming more common. Data from these herds are a valuable resource for analysis by animal model method to provide estimates of genetic parameters for estimating breeding values and evaluating the effectiveness of applied breeding programmes (Hofer et al., 1992a, b).

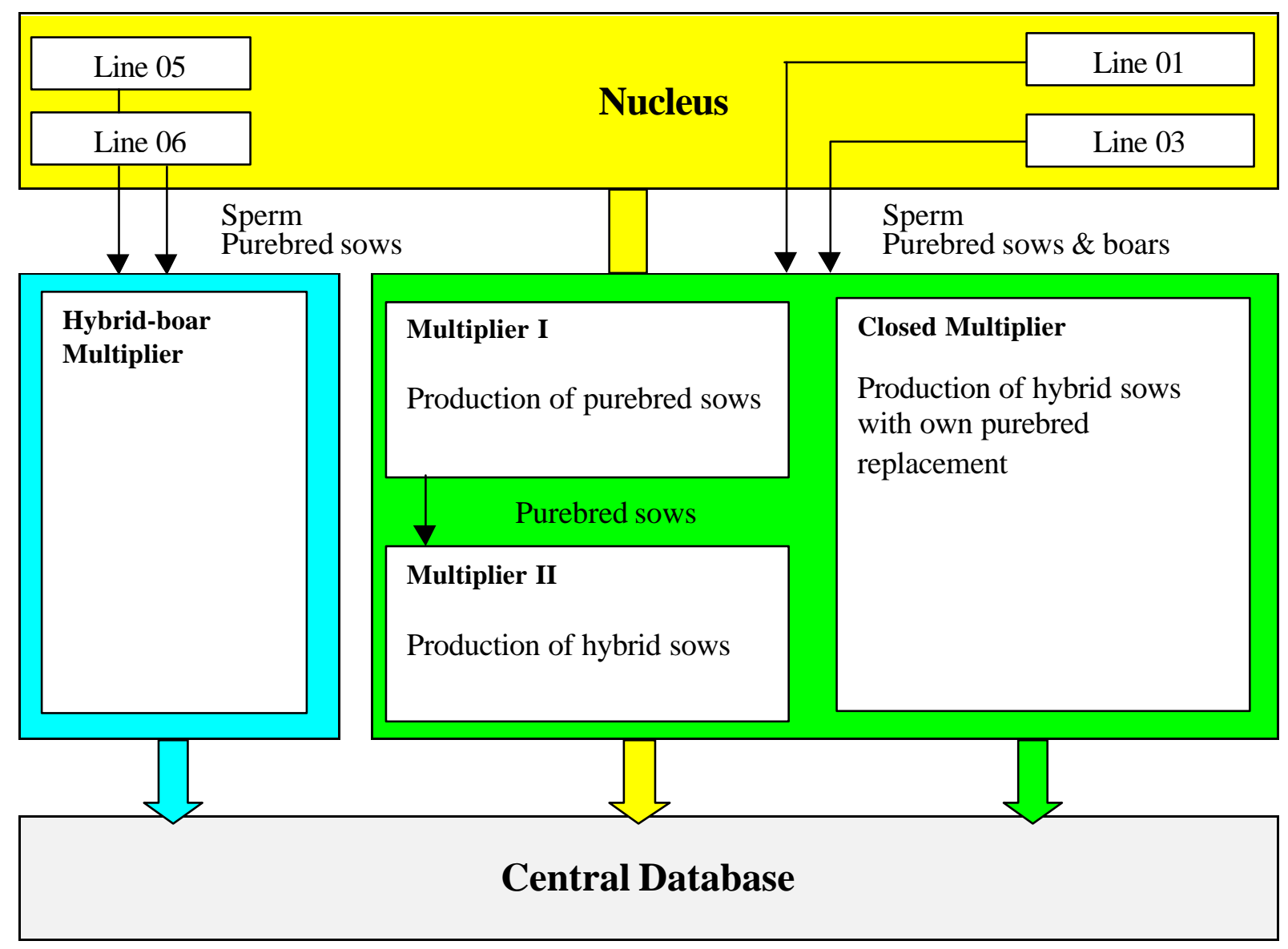

Figure 2.1. Breeding structure and data flow within the BHZP breeding programme 


\section{2. Relationship between productive and reproductive traits}

Genetic correlations between productive and reproductive traits seem to be inconsistent. Unfavourable genetic correlations between productive and reproductive traits in pigs might be one reason for the poor genetic progress made in litter size during the last years. The genetic correlations estimated by Johansson and Kennedy (1983), based on data from a litter-recording scheme, indicated that there was an unfavourable (i.e. positive) relationship between backfat thickness of sows in performance tests and their litter size. By contrast, Rydhmer et al. (1995) found a favourable (i.e. negative) genetic correlation between backfat thickness and litter size at birth of sows $\left(r_{\mathrm{g}}=-0.11\right.$ and -0.06$)$.

Cleveland et al. (1988) selected for increased lean growth, a negative but not significant response in litter size was found. While Johansson and Kennedy (1983) reported a favourable relationship between growth rate and litter size, and Kuhlers and Jungst (1993) found a small, but not significant, increase in litter size at birth when selecting Landrace pigs for a high 200-day weight.

McKay (1990) reported that litter size did not respond to index selection for reduced backfat thickness and increased growth rate. Similarly, there were no phenotypic correlations between performance-test index and litter sizes and no genetic and residual correlations between growth rate and litter size in Rydhmer et al. (1995). Tholen et al. (1996b) found conflicting genetic correlations between daily gain and litter size recorded in different parities and discrepant results between herds.

ten Napel et al. (1995a) hypothesised that genetic selection for increased daily gain, decreased backfat depth, increased litter size at birth or increased litter weight at weaning may impair normal resumption of cyclic activity after weaning, in particular after weaning the first litter. There tended to be a positive (i.e. unfavourable) genetic correlation $\left(\mathrm{r}_{\mathrm{g}}=0.11\right)$ between growth rate and farrowing interval in Rydhmer et al. (1995). Adamec and Johnson (1997) found a positive genetic correlation between weaning to conception interval and average daily gain $\left(\mathrm{r}_{\mathrm{g}}=0.18\right)$ but a negative genetic correlation between backfat thickness $\left(r_{g}=-0.07\right)$. Tholen et al. (1996b) reported that the genetic correlation between daily gain and weaning to conception interval was close to zero, but sows with a genetic disposition of a short weaning to conception interval tend to have thicker backfat, as indicated by the negative genetic correlations between weaning to conception interval, farrowing interval and backfat thickness. ten Napel and Johnson (1997) analysed the interval from weaning to farrowing as a continuous trait and estimated low genetic parameters, which would indicate that genetic selection for productive and reproductive traits does not affect the calculated intervals. 


\section{3. Genetic parameters for reproductive traits}

Since 1960 several studies have been published on the genetic analysis of sow productivity traits. In the earlier studies, genetic parameters for reproductive traits were obtained from daughter-dam regressions or half-sib correlations based on the traditional analysis of variance (Boylan et al., 1961; Urban et al., 1966; Strang and King, 1970; Edwards and Omtvedt, 1971; Revelle and Robison, 1973; Young et al., 1978; Strang and Smith, 1979; Bereskin; 1984). Since then the animal model method with restricted maximum likelihood (REML) to estimate genetic parameters for reproductive traits has become the standard method. This method that incorporates all the genetic relationships among individuals available produces smaller sampling variance, and biases due to selection could be reduced.

Reproductive traits of sows can be affected by many factors, such as breed, parity, age at first conception, mating frequency, season, age at farrowing, previous suckling period, weaning to conception interval and genetic merit (Clark and Leman, 1986a, b). However, computing power and programmes have advanced and now allow the use of animal models that include a variety of fixed and random effects simultaneously. A number of traits contribute to overall reproductive performance. These include age at first farrowing, conception rate, litter size at birth and at weaning, weaning to conception interval and so on (Haley et al., 1988).

When it comes to the influence of maternal effects upon reproductive traits, inconsistent results are found in the literature. The maternal influence on litter size has not been clearly established, but in general it has been accepted that maternal genetic effects could be negatively correlated with direct genetic effects (Haley et al., 1988). Estimates of maternal genetic effects are thus required to develop efficient selection programs (Southwood and Kennedy, 1990). Ferraz and Johnson (1993), and Southwood and Kennedy (1990) reported significant influences of maternal effects on reproductive traits. Use of a direct model, ignoring maternal breeding value, would seem sufficient in Southwood and Kennedy (1991). Haley and Lee (1992) as well as Alfonso et al. (1997) reported no significant influence of maternal effects on litter traits.

\section{3. 1. Heritabilities for litter traits}

Some researchers have doubted that selection will succeed, due to the low heritability of reproductive traits, and because their expression is limited to mature females. However, because of the ease of recording number of piglets born alive, many analyses for its genetics have been reported, although the quality and size of the data 
sets vary. The possibility and the potential for improvement of reproductive traits are considered. For most reproductive traits in pigs the reported heritabilities are low (table 2.2).

The heritability for number of piglets born in total was estimated at around 0.1 in $\mathrm{Gu}$ et al. (1989). Roehe and Kennedy (1995) estimated heritabilities for number of piglets born in total from 0.09 to 0.16 in Landrace and Yorkshire using a multiple trait animal model. Crump et al. (1997) and Adamec and Johnson (1997) reported estimates ranging from 0.09 to 0.13 for the heritability of number of piglets born in total.

Haley et al. (1988) reviewed parameter estimates for litter size, and concluded that the heritability of number of piglets born alive was around 0.1 with a repeatability of 0.15 . The estimates of heritability for number of piglets born alive using the REML method were around 0.07 and 0.12 , in Landrace and Large White respectively ( $\mathrm{Gu}$ et al., 1989). More recent estimates of heritability for the number of piglets born alive were in the range of 0.07 and 0.17 (Roehe and Kennedy, 1995; Rydhmer et al., 1995; Crump et al., 1997; Adamec and Johnson, 1997; Täubert, 1998; Bösch, 1999; Frey, 1999).

The heritabilities estimated for number of piglets weaned were in most cases lower than those for number of piglets born alive or number of piglets born in total with estimates of 0.04 to 0.11 (Roehe and Kennedy, 1995; Southwood and Kennedy, 1990). There were very few results of genetic parameters for number of piglets born dead, and these ranged from 0.04 to 0.08 (Brandt, 1984).

The repeatability model assumes that litter sizes of succeeding parities are repeated measurements of the same trait, but it has been suggested that the genetic background of litter size could be different for each parity, especially when comparing first with later parities (Haley et al., 1988). Therefore, a multivariate analysis should be performed in order to increase the efficiency of selection for litter size, and to obtain unbiased predictions of expected genetic response.

However, the estimates of heritability for number of piglets born in total and number of piglets born alive obtained by a repeatability animal model ranged from 0.05 to 0.07 (Alfonso et al., 1997). Gu et al. (1989) reported the repeatability of around 0.15 for litter traits. Frey (1999) reported the repeatabilities for number of piglets born alive as 0.17 and 0.18 . 
Table 2.2. Estimates of heritability for litter traits from the literature

\begin{tabular}{|c|c|c|c|c|c|c|}
\hline \multirow{2}{*}{ Author } & \multirow{2}{*}{ Breed $^{a}$} & \multirow{2}{*}{ Parity } & \multirow{2}{*}{$\mathrm{n}$} & \multicolumn{3}{|c|}{ Heritability } \\
\hline & & & & NPBT & NPBA & NPW \\
\hline Bösch (1999) & $\begin{array}{l}03 \\
04\end{array}$ & $\begin{array}{l}1 \\
2 \\
3 \\
1 \\
2 \\
3\end{array}$ & $\begin{array}{l}7,280 \\
3,710\end{array}$ & - & $\begin{array}{l}.086 \\
.092 \\
.173 \\
.166 \\
.122 \\
.117\end{array}$ & - \\
\hline Frey (1999) & $\begin{array}{l}\text { SL } \\
\text { ES }\end{array}$ & $\begin{array}{l}1 \\
2 \\
3 \\
1 \\
2 \\
3\end{array}$ & $\begin{array}{r}5,146 \\
4,216 \\
3,643 \\
44,028 \\
35,842 \\
29,811\end{array}$ & - & $\begin{array}{l}.10 \\
.07 \\
.17 \\
.12 \\
.13 \\
.09\end{array}$ & - \\
\hline Täubert (1998) & $\begin{array}{c}\text { ALW } \\
\text { AL } \\
\text { GL }\end{array}$ & $\begin{array}{l}1 \\
2 \\
3 \\
1 \\
2 \\
3 \\
1 \\
2 \\
3\end{array}$ & $\begin{array}{r}8,334 \\
6,440 \\
4,739 \\
3,262 \\
2,086 \\
1,280 \\
57,263 \\
45,431 \\
35,533\end{array}$ & - & $\begin{array}{l}.059 \\
.094 \\
.073 \\
.126 \\
.136 \\
.095 \\
.068 \\
.072 \\
.099\end{array}$ & - \\
\hline Tholen et al. (1996b) & $\mathrm{LW}^{*} \mathrm{~L}$ & $\begin{array}{l}1 \\
2 \\
3 \\
\end{array}$ & $\begin{array}{l}2,440 \\
6,050\end{array}$ & - & $\begin{array}{l}.10-.12 \\
.11-.13 \\
.09-.16\end{array}$ & - \\
\hline Rydhmer et al. (1995) & $\mathrm{Y}$ & $\begin{array}{l}1 \\
2 \\
\end{array}$ & 4,068 & - & $\begin{array}{l}.13 \\
.12 \\
\end{array}$ & - \\
\hline $\begin{array}{l}\text { Roehe and Kennedy } \\
\text { (1995) }\end{array}$ & $\mathrm{Y}$ & $\begin{array}{l}1 \\
2 \\
3 \\
4 \\
1 \\
2 \\
3 \\
4\end{array}$ & $\begin{array}{r}11,782 \\
8,084 \\
5,904 \\
4,587 \\
16,306 \\
11,120 \\
8,301 \\
6,314\end{array}$ & $\begin{array}{l}.090 \\
.143 \\
.094 \\
.092 \\
.098 \\
.091 \\
.123 \\
.163\end{array}$ & $\begin{array}{l}.072 \\
.111 \\
.085 \\
.135 \\
.086 \\
.096 \\
.116 \\
.141\end{array}$ & $\begin{array}{l}.066 \\
.073 \\
.110 \\
.082 \\
.072 \\
.080 \\
.060 \\
.039\end{array}$ \\
\hline Irgang et al. (1994) & $\begin{array}{c}\mathrm{D} \\
\mathrm{L} \\
\mathrm{LW}\end{array}$ & $\begin{array}{l}1 \\
2 \\
3 \\
1 \\
2 \\
3 \\
1 \\
2 \\
3\end{array}$ & $\begin{array}{r}1,817 \\
1,202 \\
781 \\
5,799 \\
3,576 \\
2,356 \\
4,561 \\
2,862 \\
2,004\end{array}$ & - & $\begin{array}{l}.147 \\
.113 \\
.101 \\
.146 \\
.208 \\
.021 \\
.094 \\
.152 \\
.177\end{array}$ & - \\
\hline $\begin{array}{l}\text { Southwood and } \\
\text { Kennedy (1990) }\end{array}$ & $\begin{array}{l}\mathrm{Y} \\
\mathrm{L}\end{array}$ & $\begin{array}{l}1 \\
1\end{array}$ & $\begin{array}{r}8,825 \\
12,302 \\
\end{array}$ & $\begin{array}{l}.127 \\
.133 \\
\end{array}$ & $\begin{array}{l}.131 \\
.086\end{array}$ & $\begin{array}{l}.100 \\
.068\end{array}$ \\
\hline
\end{tabular}

${ }^{a}$ AL; Australian Landrace, ALW; Australian Large White, D; Duroc, ES; Edelschwein,

GL; German Landrace, L; Landrace, LW; Large White, SL; Swiss Landrace, Y; Yorkshire 


\section{3. 2. Heritabilities for calculated intervals}

One of the factors that has an effect on litter traits are intervals such as age at first conception and previous interval between weaning and conception (Clark and Leman, 1986a, b). The variation of weaning to conception interval was considered to be mostly influenced by environmental factors. Estrus expression, estrus length and time of insemination relative to ovulation may play a role in this period. Obviously weaning to conception interval affects the farrowing interval in the same reproductive cycle. Farrowing interval is a combination of several traits and management factors. Farrowing interval consists of three periods: suckling period, weaning to conception interval and gestation length. If estrus symptoms after weaning are weak, the first estrus may pass undetected and farrowing interval will immediately become 3 weeks longer.

In general, the interval between weaning and conception consists of weaning to estrus and estrus to successful mating intervals. Parameter estimates for weaning to estrus interval are expected to be similar to those for weaning to service interval because only a small amount of variation is added to weaning to estrus interval due to mating policy. Because weaning to service interval is part of weaning to conception interval, a great proportion of genetic liability for weaning to conception interval is assumed to be associated with weaning to estrus (or service) interval due to an existing autocorrelation between the two traits (Adamec and Johnson, 1997).

Estimates of heritability for weaning to service interval were around 0.14 in Adamec and Johnson (1997). Fahmy et al. (1979) and ten Napel et al. (1995b) found comparably larger estimates, between 0.22 and 0.44 , of heritability for weaning to estrus interval. Estimates of heritability for weaning to conception interval ranged from 0.06 to 0.10 (Adamec and Johnson, 1997). Rydhmer et al. (1995) estimated a heritability of 0.3 for age at first farrowing. Johansson and Kennedy (1985) reported a heritability of 0.1 for age at first farrowing. Estimated heritabilities for farrowing interval were 0.06 for Landrace sows and 0.09 for Yorkshire sows (Johansson and Kennedy, 1985). Adamec and Johnson (1997) estimated the heritability for farrowing interval of 0.07. Haley et al. (1988) reviewed the estimates for farrowing interval within a range of 0.04 to 0.22 . Estimates of heritability for farrowing interval were 0.17 by Johansson (1981) and 0.1 by Rydhmer et al. (1995).

Since the distribution of calculated intervals was left skewed, several researchers have tried to modify this characteristic. ten Napel et al. (1998) derived three new traits, which were normal, prolonged and incidence of a prolonged interval, from weaning to estrus. The estimates of heritability for normal, prolonged interval and incidence of prolonged intervals were $0.18,0.17$ and 0.27 respectively. Frey (1999) proposed a 
logarithmic transformation of the intervals.

\section{3. 3. Genetic correlations between reproductive traits}

The genetic correlations between reproductive traits and between traits in different parities are important for defining optimum evaluation procedures for selection programmes. Genetic correlations between parities of one, or approximately one, indicate that genetic gains in first parity sows would assure genetic gains in later parities, with the benefits of reduced generation interval and increased selection intensity, or that repeatability models could be used to evaluate reproductive traits. However, low genetic correlations indicate that traits from different parities should be treated as different traits, and that other genetic evaluation methods, such as multipletraits animal models, should be used to estimate breeding values.

Irgang et al. (1994) reported low genetic correlations for litter size between first and second parities in the range of 0.32 to 0.48 , but higher correlations between first and third, and second and third parities, in the range of 0.77 to 1.00 , respectively. These estimates for litter size between first and second parity are lower than those reported by Johansson and Kennedy (1985) and in contrast with estimates reported by Haley et al. (1988). The genetic correlation between number of piglets born alive in first parity and that in second parity was estimated to be 0.7 (Rydhmer et al., 1995). Roehe and Kennedy (1995) reported that genetic correlations for litter traits between adjacent parities were substantially less than one, and that heritability increases with parity in Landrace sows. Brandt (1984) reported a genetic correlation for number of piglets born alive between first and second parities of 0.91. Alfonso et al. (1997) estimated genetic correlations between parities with bivariate analyses and found them close to one and similar for number of piglets born alive and number of piglets born in total in the first five parities.

Genetic correlations between number of piglets born in total and number of piglets born alive were high (Johansson and Kennedy, 1985; Roehe and Kennedy, 1995), so genetic improvement of number of piglets born in total would also increase number of piglets born alive. However, selection for number of piglets born in total always has the risk of increasing number of pigs born dead.

The genetic correlation between number of piglets born alive and number of piglets weaned was estimated low by Roehe and Kennedy (1995). This correlation may be influenced by crossforstering. Number of piglets weaned is of greater importance than number of piglets born alive from an economic point of view (Haley et al., 1988). However, selection for number of piglets weaned is very difficult to record under on 
farm-testing conditions in breeding herds that usually practise crossfostering.

The genetic correlation between number of piglets born in total and number of piglets weaned was consistently lower than that between number of piglets born alive and number of piglets weaned, as can be expected because the difference between number of piglets born in total and number of piglets born alive is number of dead pigs (Roehe and Kennedy, 1995).

There are few estimates for genetic correlations between litter size and other reproductive traits such as age at first farrowing and farrowing interval. The residual correlation $\left(\mathrm{r}_{\mathrm{e}}=0.15\right)$ between age at first farrowing and size of first parity was positive (Rydhmer et al., 1995). Southwood and Kennedy (1991) estimated a positive regression of first litter size on age at farrowing averaging 0.2 piglets/month. Negative relationships between weaning to estrus interval and subsequent litter size and farrowing rate have been found by Kemp and Soede (1996).

Genetic correlations of weaning to service interval with number of piglets born in total, number of piglets born alive and number of piglets weaned were found to be 0.13, 0.08 and 0.13 respectively (Adamec and Johnson, 1997). Similar relationships between weaning to estrus interval and litter size were previously reported in studies by Farmy et al (1979) and ten Napel et al. (1995b). Maurer et al. (1985) found the relationship to be non-linear (quadratic and cubic).

ten Napel et al. (1997) reported that correlated responses for litter size to a selection for a short weaning to estrus interval are small and depend highly on the environment in which the population is selected. Genetic correlations between weaning to conception interval and litter traits were zero or slightly negative in Adamec and Johnson (1997).

The phenotypic correlations between weaning to conception interval and farrowing interval measured at different parities were close to zero (Tholen et al., 1996a). Management factors obviously influence this relationship to a high extent. Higher phenotypic correlations could be found between weaning to conception interval and farrowing interval in the same reproductive cycle. The genetic correlation between weaning to conception interval and farrowing interval by Tholen et al. (1996a) did not differ from unity.

First weaning to conception interval and farrowing interval were negatively correlated to number of piglets born alive in first and third parity, whereas the genetic correlation to number of piglets born alive in second parity was positive (Tholen et al., 1996b). Rydhmer et al. (1995) estimated negative genetic correlations between number of 
piglets born alive and farrowing interval in first and second parity of -0.03 and -0.10 respectively. In the study of Tholen et al. (1996b) the genetic correlations between weaning to conception interval or farrowing interval and number of piglets born alive recorded in first parity were both favourable. In second and third parity the genetic correlations between weaning to conception interval or farrowing interval and number of piglets born alive were opposite in sign. 


\section{Material and Methods}

\section{1. Data}

\section{1. 1. Performance test records}

The data used in this research included performance test records from purebred sows in multiplier farms of the Bundeshybridzuchtprogramm (BHZP). The information analysed related to young sows only tested between January 1995 and August 1999. Beside the animal number, farm number, birth date and breed the following traits were available:

1) Test weight in $\mathrm{kg}$ of sow

2) Average daily gain of sow

3) Backfat thickness was measured at three points based on ultrasonic measurement. The average backfat thickness was calculated.

4) Number of piglets born in total and parity of the litter in which the sow was born were also available.

\section{1. 1. 1. Characteristics of the performance test records}

The total number of performance test records was 96,983. From these records only young sows tested were maintained. And animals with backfat thickness under $5 \mathrm{~mm}$ were deleted. Animals were deleted if test farm was different to birth farm. The minimum number of observations per farm had to be more than 100 . The pedigree information had to be available to the performance test records. The reproductive trait records of dams of young sows had to be available to performance test records, all the records without reproductive trait records of dams were deleted: 91,909 observations could be maintained which had been tested in 55 farms. The reduction of data and distribution over the year of test, parity and piglets born in total in the birth litter are shown in tables 3.1 and 3.2. For the analysed young sows, the mean age at test was 166 days $(\mathrm{SD}=10)$ and the mean weight was $91.9 \mathrm{~kg}(\mathrm{SD}=9.6)$. Mean values and standard deviations for traits are presented in table 3.3. 
Table 3.1. Reduction of performance test records because of biological limits and pedigree

\begin{tabular}{lcc}
\hline & No. of records & Reduction(\%) \\
\hline Total & 96,983 & \\
Biological limits & 92,249 & $4,734(4.8)$ \\
Pedigree & 91,955 & $249(0.3)$ \\
Reproductive records & 91,909 & $46(0.1)$ \\
\hline
\end{tabular}

Table 3.2. Distribution of observations in edited performance test records

\begin{tabular}{|c|c|c|c|c|c|c|c|}
\hline \multicolumn{2}{|c|}{ Test year } & \multicolumn{2}{|c|}{ Parity of dam } & \multicolumn{2}{|c|}{$\begin{array}{l}\text { Number of piglets } \\
\text { in the birth litter }\end{array}$} & \multicolumn{2}{|c|}{$\begin{array}{c}\text { Number of records } \\
\text { in farm }\end{array}$} \\
\hline 1995 & 15,821 & 1 & 19,304 & $\leq 5$ & 2,256 & $55^{\mathrm{a}}$ & 91,909 \\
\hline 1996 & 18,061 & 2 & 21,007 & 6 & 2,273 & & \\
\hline 1997 & 19,357 & 3 & 17,763 & 7 & 3,726 & Mean & 1,671 \\
\hline 1998 & 22,451 & 4 & 13,393 & 8 & 5,804 & Min & 107 \\
\hline \multirow[t]{9}{*}{1999} & 16,219 & 5 & 9,188 & 9 & 8,717 & Max & 6,974 \\
\hline & & $6 \leq$ & 11,254 & 10 & 13,053 & & \\
\hline & & & & 11 & 14,073 & & \\
\hline & & & & 12 & 14,180 & & \\
\hline & & & & 13 & 10,768 & & \\
\hline & & & & 14 & 7,676 & & \\
\hline & & & & 15 & 4,900 & & \\
\hline & & & & 16 & 2,360 & & \\
\hline & & & & $17 \leq$ & 2,123 & & \\
\hline
\end{tabular}

${ }^{\mathrm{a}}$ Number of farms. 
Table 3.3. Mean values (Mean), standard deviations (SD) minimum values (Min) and maximum values (Max) for the traits $(n=91,909)$

\begin{tabular}{lrrrr}
\hline \multicolumn{1}{c}{ Traits } & Mean & \multicolumn{1}{c}{ SD } & Min & Max \\
\hline Age at test, days & 166.24 & 10.27 & 115 & 267 \\
Weight at test, kg & 91.85 & 9.59 & 41 & 154 \\
Average daily gain, g & 551.87 & 56.29 & 264 & 820 \\
Average backfat thickness, mm & 9.27 & 1.55 & 5 & 20 \\
Backfat thickness 1, mm & 9.90 & 1.85 & 5 & 22 \\
Backfat thickness 2, mm & 8.73 & 1.53 & 5 & 19 \\
Backfat thickness 3, mm & 9.17 & 1.63 & 5 & 21 \\
Size of birth litter (NPBT), piglets & 11.16 & 2.71 & 1 & 24 \\
\hline
\end{tabular}

\section{1. 2. Litter records}

The data used in this research included the litter records from purebred Landrace sows obtained from multiplier farms of the BHZP. The information analysed related to sows farrowed between April 1991 and August 1999.

The reproductive performance set in place with parity and breeds were:

1) Litter traits

- Number of piglets born in total was the sum of number of piglets born alive and dead (NPBT).

- Number of piglets born alive (NPBA).

- Number of piglets born dead (NPBD).

- Number of piglets weaned included number of adopted piglets from but excluded number of piglets transferred to other sows (NPW). 
2) Calculated intervals

- Age at first mating: first mating date - birth date (AFM)

- Age at first farrowing: first farrowing date - birth date (AFF)

- Gestation length: farrowing date - successful mating date (GL)

- Suckling period: weaning date - farrowing date (SP)

- Weaning to conception interval: successful mating date - weaning date in the previous litter (WCI)

- Farrowing interval: farrowing date - farrowing date in the previous litter (FI)

The calculated intervals are described in figure 3.1. The farrowing interval is dependent on the suckling period, the weaning to conception interval and the gestation length. The weaning to conception interval is dependent on the return and mating time. The suckling period has a mean value of 27 days $(\mathrm{SD}=4.7)$, and gestation length a mean value of 115 days $(\mathrm{SD}=1.54)$. Farrowing interval is mainly dependent on the weaning to conception interval.

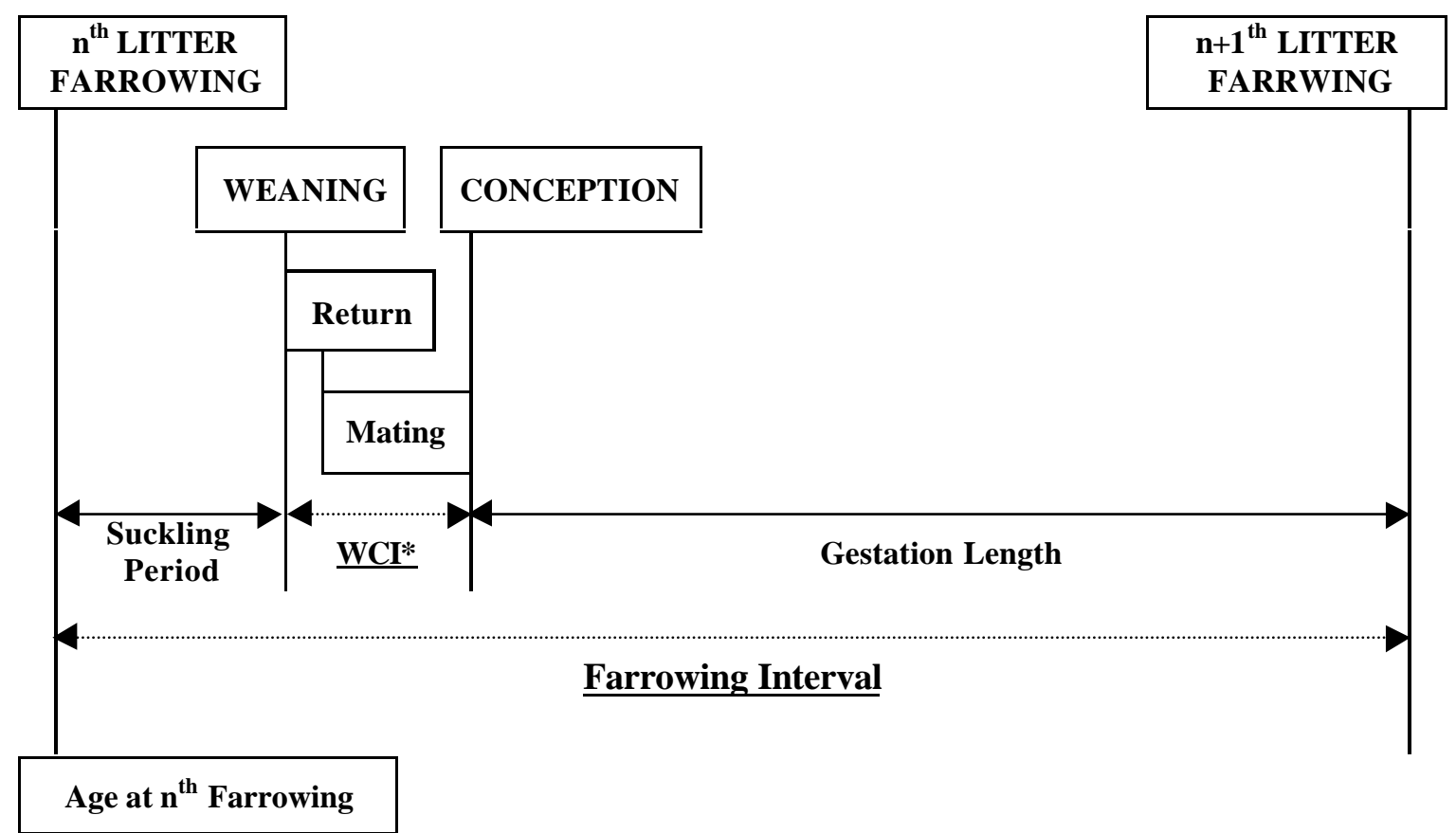

* WCI: weaning to conception interval

Figure 3.1. Description of the calculated intervals 


\section{1. 2. 1. Characteristics of the litter records}

Only sows that had at least a first litter record were considered for the analysis. Additionally, sows that were not mated with Landrace (01) or Large White (03) boars were excluded. Records of all consecutive parities of sows beginning with first parity were included in the data set. Records were excluded if one of the traits exceeded unrealistic biological limits.

The ranges were:

- Age at first farrowing date 278 - 450 days

- Number of piglets born in total 1 to 22 pigs

- Gestation length 104 - 125 days

- Suckling period 16 - 60 days

- Weaning to conception interval 1 - 60days.

- Farrowing interval 130 - 225 days

Only farms with a minimum number of 100 litters were maintained. Pedigree information had to be available to the litter records. The reduction of data and distribution over service boar line, year of farrowing and parity are shown in table 3.4 and 3.5 .

Table 3.4. Reduction of litter records because of biological limits and pedigree

\begin{tabular}{lcc}
\hline & No. of litters & Reduction (\%) \\
\hline Total & 119,554 & - \\
Biological limits & 91,074 & $28,480(23.8)$ \\
(excluding missing $1^{\text {st }}$ litter) & 90,908 & $116(0.1)$ \\
Pedigree & & \\
\hline
\end{tabular}


Table 3.5. Distribution of litters in edited litter records

\begin{tabular}{|c|c|c|c|c|c|c|c|}
\hline \multicolumn{2}{|c|}{ Service boar line } & \multicolumn{2}{|c|}{ Year of farrowing } & \multicolumn{2}{|c|}{ Parity } & \multicolumn{2}{|c|}{$\begin{array}{c}\text { Number of records } \\
\text { in farm } \\
\end{array}$} \\
\hline 01 & 29,393 & 1991 & 1,800 & 1 & 25,423 & $58^{\mathrm{a}}$ & 90,908 \\
\hline \multirow[t]{8}{*}{03} & 61,515 & 1992 & 5,728 & 2 & 19,421 & & \\
\hline & & 1993 & 8,794 & 3 & 15,230 & Mean & 1,567 \\
\hline & & 1994 & 9,929 & $4 \leq$ & 30,834 & Min & 226 \\
\hline & & 1995 & 11,089 & & & Max & 5,551 \\
\hline & & 1996 & 12,552 & & & & \\
\hline & & 1997 & 14,361 & & & & \\
\hline & & 1998 & 16,087 & & & & \\
\hline & & 1999 & 10,568 & & & & \\
\hline
\end{tabular}

${ }^{\mathrm{a}}$ Number of farms.

The number of observations, the mean values and the standard deviations for traits are presented in table 3.6. The mean age at first mating was calculated at 236 days and the standard deviation was 26 days. The mean age at first farrowing was calculated at 351 days and the standard deviation was 26 days. 
Table 3.6. Number of observations (N), mean values (Mean), standard deviations (SD), minimum values (Min) and maximum values (Max) for the traits within parity

\begin{tabular}{|c|c|c|c|c|c|c|}
\hline Traits & Parity & $\mathrm{N}$ & Mean & SD & Min & $\operatorname{Max}$ \\
\hline \multirow{5}{*}{$\begin{array}{l}\text { Number of piglets born in total } \\
\text { (NPBT) }\end{array}$} & 1 & 25,423 & 9.45 & 2.56 & 1 & 22 \\
\hline & 2 & 19,421 & 10.13 & 2.84 & 1 & 22 \\
\hline & 3 & 15,230 & 10.55 & 2.77 & 1 & 22 \\
\hline & $4 \leq$ & 30,834 & 10.73 & 2.88 & 1 & 22 \\
\hline & total & 90,908 & 10.21 & 2.81 & 1 & 22 \\
\hline \multirow{5}{*}{$\begin{array}{l}\text { Number of piglets born alive } \\
\text { (NPBA) }\end{array}$} & 1 & 25,423 & 8.87 & 2.56 & 1 & 18 \\
\hline & 2 & 19,421 & 9.61 & 2.75 & 1 & 20 \\
\hline & 3 & 15,230 & 9.96 & 2.68 & 1 & 19 \\
\hline & $4 \leq$ & 30,834 & 9.95 & 2.75 & 1 & 22 \\
\hline & total & 90,908 & 9.58 & 2.73 & 1 & 22 \\
\hline \multirow{5}{*}{$\begin{array}{l}\text { Number of piglets born dead } \\
\text { (NPBD) }\end{array}$} & 1 & 25,423 & 0.57 & 1.05 & 0 & 15 \\
\hline & 2 & 19,421 & 0.53 & 0.98 & 0 & 12 \\
\hline & 3 & 15,230 & 0.59 & 1.04 & 0 & 14 \\
\hline & $4 \leq$ & 30,834 & 0.78 & 1.21 & 0 & 13 \\
\hline & total & 90,908 & 0.64 & 1.10 & 0 & 15 \\
\hline \multirow{5}{*}{$\begin{array}{l}\text { Number of piglets weaned } \\
\text { (NPW) }\end{array}$} & 1 & 24,252 & 8.47 & 1.97 & 0 & 19 \\
\hline & 2 & 18,876 & 8.99 & 1.91 & 0 & 16 \\
\hline & 3 & 14,783 & 9.14 & 1.88 & 0 & 17 \\
\hline & $4 \leq$ & 29,816 & 8.82 & 1.91 & 0 & 18 \\
\hline & total & 87,727 & 8.85 & 1.94 & 0 & 19 \\
\hline \multirow{5}{*}{$\begin{array}{l}\text { Gestation length } \\
\text { (GL) }\end{array}$} & 1 & 25,423 & 115.17 & 1.57 & 105 & 125 \\
\hline & 2 & 19,421 & 114.99 & 1.54 & 104 & 124 \\
\hline & 3 & 15,230 & 114.97 & 1.51 & 107 & 124 \\
\hline & $4 \leq$ & 30,834 & 115.06 & 1.51 & 108 & 125 \\
\hline & total & 90,908 & 115.06 & 1.54 & 104 & 125 \\
\hline \multirow{5}{*}{$\begin{array}{l}\text { Suckling period } \\
\text { (SP) }\end{array}$} & 1 & 24,252 & 26.83 & 4.85 & 16 & 59 \\
\hline & 2 & 18,876 & 26.47 & 4.67 & 16 & 60 \\
\hline & 3 & 14,783 & 26.47 & 4.59 & 16 & 57 \\
\hline & $4 \leq$ & 29,816 & 26.42 & 4.65 & 16 & 58 \\
\hline & total & 87,727 & 26.55 & 4.70 & 16 & 60 \\
\hline \multirow{4}{*}{$\begin{array}{l}\text { Weaning to conception interval } \\
\text { (WCI) }\end{array}$} & 12 & 19,212 & 12.71 & 13.52 & 1 & 60 \\
\hline & 23 & 15,108 & 9.22 & 10.21 & 1 & 60 \\
\hline & $34 \leq$ & 30,679 & 8.23 & 9.17 & 1 & 60 \\
\hline & total & 64,999 & 9.79 & 11.03 & 1 & 60 \\
\hline \multirow{4}{*}{$\begin{array}{l}\text { Farrowing interval } \\
(\mathrm{FI})\end{array}$} & 12 & 19,421 & 154.60 & 14.38 & 130 & 225 \\
\hline & 23 & 15,230 & 150.86 & 11.25 & 130 & 219 \\
\hline & $34 \leq$ & 30,679 & 149.95 & 10.23 & 130 & 212 \\
\hline & total & 65,485 & 151.54 & 12.00 & 130 & 225 \\
\hline
\end{tabular}




\section{2. Statistical analysis}

\section{2. 1. The analysed data material}

For the genetic analysis of litter records in this study only the first three parities of sows were included. Table 3.7 shows the number of litters in the analysed data material and their distribution over service boar line, parity and year of farrowing. There were 25,423 sows with 60,074 litters from 58 farms. The reproductive traits analysed were the litter traits: number of piglets born in total (NPBT), number of piglets born alive (NPBA), number of piglets born dead (NPBD), number of piglets weaned (NPW) and the intervals: farrowing interval (FI), weaning to conception interval (WCI). Mating type was ignored because all mating was by artificial insemination.

The distribution of sows over farm, sire and dam is given in table 3.8. The minimum number of sows per farm was more than 124 . The mean numbers of sows per sire and dam were 47 and 3 respectively.

Table 3.7. Distribution of litters in analysed data material

\begin{tabular}{|c|c|c|c|c|c|}
\hline \multicolumn{2}{|c|}{ Service boar line } & \multicolumn{2}{|c|}{ Parity } & \multicolumn{2}{|c|}{ Year of farrowing } \\
\hline 01 & 19,721 & 1 & 25,423 & 1991 & 1,800 \\
\hline \multirow[t]{8}{*}{03} & 40,353 & 2 & 19,421 & 1992 & 5,188 \\
\hline & & 3 & 15,230 & 1993 & 5,956 \\
\hline & & & & 1994 & 5,874 \\
\hline & & & & 1995 & 6,934 \\
\hline & & & & 1996 & 8,046 \\
\hline & & & & 1997 & 9,331 \\
\hline & & & & 1998 & 10,128 \\
\hline & & & & 1999 & 6,817 \\
\hline
\end{tabular}

Table 3.8. Distribution of sows over farm, sire and dam

\begin{tabular}{lrcrr}
\hline & $\mathrm{N}$ & $\begin{array}{c}\text { average number } \\
\text { of sows/daughters }\end{array}$ & Min & Max \\
\hline Farm & 58 & 438.33 & 124 & 1,512 \\
Sire & 542 & 46.91 & 1 & 356 \\
Dam & 8,356 & 3.04 & 1 & 24 \\
\hline
\end{tabular}




\section{2. 2. Models}

\section{2. 2. 1. Model for litter size in the birth litter on productive traits}

The performance test records were analysed to determine the effect of litter size in the birth on average daily gain and backfat thickness using the GLM procedure of SAS. The model was as follows:

$$
Y_{i j k}=\mu+H_{Y} S_{i}+L_{j}+b\left(\mathbf{x}_{i j k}-\overline{\mathbf{x}}\right)+\mathbf{e}_{i j k}
$$

where:

$$
\begin{aligned}
& Y_{i j k}=\text { ijk-th observation of productive trait } \\
& \mu \quad=\text { population mean } \\
& \text { HYS }_{\mathrm{i}} \quad=\text { fixed effect of } \mathrm{i} \text {-th herd-year-season class } \\
& \text { (test season divided into quarters of year:1-3, 4-6, 7-9, 10-12) } \\
& \mathrm{L}_{\mathrm{j}} \quad=\text { fixed effect of } \mathrm{j} \text {-th litter size in the birth litter }(\mathrm{j}=5,6, \ldots, 16,17) \\
& b_{k}\left(x_{i j k}-\bar{x}\right)=\text { test weight as a covariate for backfat thickness only } \\
& \mathrm{e}_{\mathrm{ijk}} \quad=\text { random residual effects, } \mathrm{e}_{\mathrm{ijk}} \sim \mathrm{N}\left(0, \sigma^{2}{ }_{\mathrm{e}}\right)
\end{aligned}
$$

\section{2. 2. 2. Model for the tests of fixed effects on litter traits}

The tests of significance for all fixed effects on litter traits were done using the GLM procedure of SAS.

The model was as follows:

$$
Y_{i j k l}=\mu+H_{Y} S_{i}+B_{j}+P_{k}+b_{k}\left(\mathbf{x}_{i j k l}-\bar{x}\right)+\mathbf{e}_{i j k l}
$$

where:

$$
\begin{aligned}
& Y_{i j k l} \quad=\text { ijkl-th observation of litter trait } \\
& \mu \quad=\text { population mean } \\
& \text { HYS }_{\mathrm{i}} \quad=\text { fixed effect of } \mathrm{i} \text {-th herd-year-season class } \\
& \text { (farrowing season divided into quarters of year:1-3, 4-6, 7-9, 10-12) } \\
& B_{j} \quad=\text { fixed effect of } j \text {-th service boar line }(j=1,2) \\
& \mathrm{P}_{\mathrm{k}} \quad=\text { fixed effect of } \mathrm{k} \text {-th parity }(\mathrm{k}=1,2,3) \\
& \mathrm{b}_{\mathrm{k}}\left(\mathrm{x}_{\mathrm{ijkl}}-\overline{\mathrm{X}}\right)=\text { age at first farrowing or farrowing interval within parity } \\
& \text { as a covariate for litter trait } \\
& \mathrm{e}_{\mathrm{ijkl}}=\text { random residual effects, } \mathrm{e}_{\mathrm{ijkl}} \sim \mathrm{N}\left(0, \sigma_{\mathrm{e}}^{2}\right)
\end{aligned}
$$




\section{2. 2. 3. Models for estimation of parameters}

Variance and covariance components, genetic parameters and breeding values were estimated by the following multiple-trait and repeatability animal models, using the restricted maximum likelihood (REML) of the VCE 4.2.5 (Groeneveld, 1998), and PEST 3.1 (Groeneveld, 1990) programme packages.

Model 1a: for the productive traits

$$
Y_{i j k l}=\mu+H_{Y} S_{i}+b\left(x_{i j k l}-\bar{x}\right)+c_{j}+a_{k}+e_{i j k l}
$$

where:

$$
\begin{array}{ll}
Y_{i j k l}= & \text { ijkl-th observation of productive trait } \\
& \text { (average daily gain or backfat thickness) } \\
= & \text { population mean } \\
\mu & \text { fixed effect of } \mathrm{i} \text {-th test herd-year-season class } \\
& \text { (test season divided into quarter of year: 1-3, 4-6, 7-9, 10-12) } \\
\mathrm{HYS}_{\mathrm{i}}= & \text { test weight as a covariate for backfat thickness only } \\
\mathrm{b}\left(\mathrm{x}_{\mathrm{ijkl}}-\overline{\mathrm{x}}\right)= & \text { random effect of } \mathrm{j} \text {-th common environment } \\
\mathrm{c}_{\mathrm{j}} & \text { random additive genetic effect of } \mathrm{k}-\text { th animal } \\
\mathrm{a}_{\mathrm{k}} & \text { random residual effects, } \mathrm{e}_{\mathrm{ijkl}} \sim \mathrm{N}\left(0, \sigma_{\mathrm{e}}^{2}\right) \\
\mathrm{e}_{\mathrm{ijkl}} &
\end{array}
$$

Model 1b: as Model 1a + fixed effect of litter size in the birth litter

Model 1c: as Model 1a + litter size in the birth litter as a covariate

Model 1d: as Model 1a with pre-adjusted daily gain for litter size in the birth litter 
Model 2: for the litter traits, each parity separately

$$
Y_{i j k l}=\mu+H_{Y} S_{i}+B_{j}+b\left(\mathbf{x}_{i j k l}-\overline{\mathbf{x}}\right)+\mathbf{a}_{k}+\mathbf{e}_{i j k l}
$$

where:

$Y_{i j k l} \quad=$ ijkl-th observation of litter trait

$\mu \quad=$ population mean

$\mathrm{HYS}_{\mathrm{i}}=$ fixed effect of $\mathrm{i}$-th herd-year-season class

(farrowing season divided into quarters of year:1-3, 4-6, 7-9, 10-12)

$\mathrm{B}_{\mathrm{j}} \quad=$ fixed effect of $\mathrm{j}$-th service boar line $(\mathrm{j}=1,2)$

$\mathrm{b}\left(\mathrm{x}_{\mathrm{ijkl}}-\overline{\mathrm{X}}\right)=$ age at first farrowing or farrowing interval as a covariate for litter trait

$\mathrm{a}_{\mathrm{k}} \quad=$ random additive genetic effect of $\mathrm{k}$-th animal

$\mathrm{e}_{\mathrm{ijkl}}=$ random residual effects, $\mathrm{e}_{\mathrm{ijkl}} \sim \mathrm{N}\left(0, \sigma_{\mathrm{e}}^{2}\right)$

Model 3: for the intervals, each parity separately

$$
Y_{i j k l}=\boldsymbol{\mu}+\mathbf{H Y S}_{\mathrm{i}}+\mathbf{B}_{\mathrm{j}}+\mathbf{a}_{\mathrm{k}}+\mathbf{e}_{\mathrm{ijkl}}
$$

where:

$$
\begin{aligned}
& Y_{i j k l} \quad=\text { ijkl-th observation of interval } \\
& \mu \quad=\text { population mean } \\
& \mathrm{HYS}_{\mathrm{i}}=\text { fixed effect of } \mathrm{i} \text {-th herd-year-season class } \\
& \text { (farrowing season divided into quarters of year:1-3, 4-6, 7-9, 10-12) } \\
& \mathrm{B}_{\mathrm{j}} \quad=\text { fixed effect of } \mathrm{j} \text {-th service boar line }(\mathrm{j}=1,2) \\
& \mathrm{a}_{\mathrm{k}} \quad=\text { random additive genetic effect of } \mathrm{k} \text {-th animal } \\
& \mathrm{e}_{\mathrm{ijkl}}=\text { random residual effects, } \mathrm{e}_{\mathrm{ijkl}} \sim \mathrm{N}\left(0, \sigma_{\mathrm{e}}^{2}\right)
\end{aligned}
$$


Model 4: Repeatability model for litter traits, parities 1 to 3

$$
Y_{i j k l m n}=\mu+H_{Y} S_{i}+B_{j}+P_{k}+\mathbf{p e}_{1}+a_{m}+\mathbf{e}_{i j k l m n}
$$

where:

$Y_{i j k l m n}=$ ijklmn-th observation of litter trait

$\mu \quad=$ population mean

HYS $_{\mathrm{i}} \quad=$ fixed effect of $\mathrm{i}$-th herd-year-season class

(farrowing season divided into quarters of year:1-3, 4-6, 7-9, 10-12)

$B_{j} \quad=$ fixed effect of $j$-th service boar line $(j=1,2)$

$\mathrm{P}_{\mathrm{k}} \quad=$ fixed effect of $\mathrm{k}$-th parity $(\mathrm{k}=1,2,3)$

pe $_{1} \quad=$ random effect of 1-th permanent environment

$\mathrm{a}_{\mathrm{m}} \quad=$ random additive genetic effect of $\mathrm{m}$-th animal

$\mathrm{e}_{\mathrm{ijklmn}}=$ random residual effects, $\mathrm{e}_{\mathrm{ijklmn}} \sim \mathrm{N}\left(0, \sigma_{\mathrm{e}}^{2}\right)$ 


\section{Results}

\section{1. The effect of litter size in the birth litter on parameters for backfat thickness and average daily gain of young sows tested}

Figure 4.1 shows the least square means of backfat thickness and average daily gain of young sows tested under the effect of litter size in thier birth litter (number of piglets born in total). The influence of litter size in the birth litter on the productive traits, backfat thickness and daily gain of young sows tested is highly significant $(p<0.001)$, although figure 4.1 does not show any trend or tendency for backfat thickness. For daily gain a clear linear trend can be seen with a decrease of daily gain with increasing number of piglets in the birth litter. The linear regression coefficient of number of piglets in the birth litter on daily gain is $-1.8 \mathrm{~g}$ per piglet.

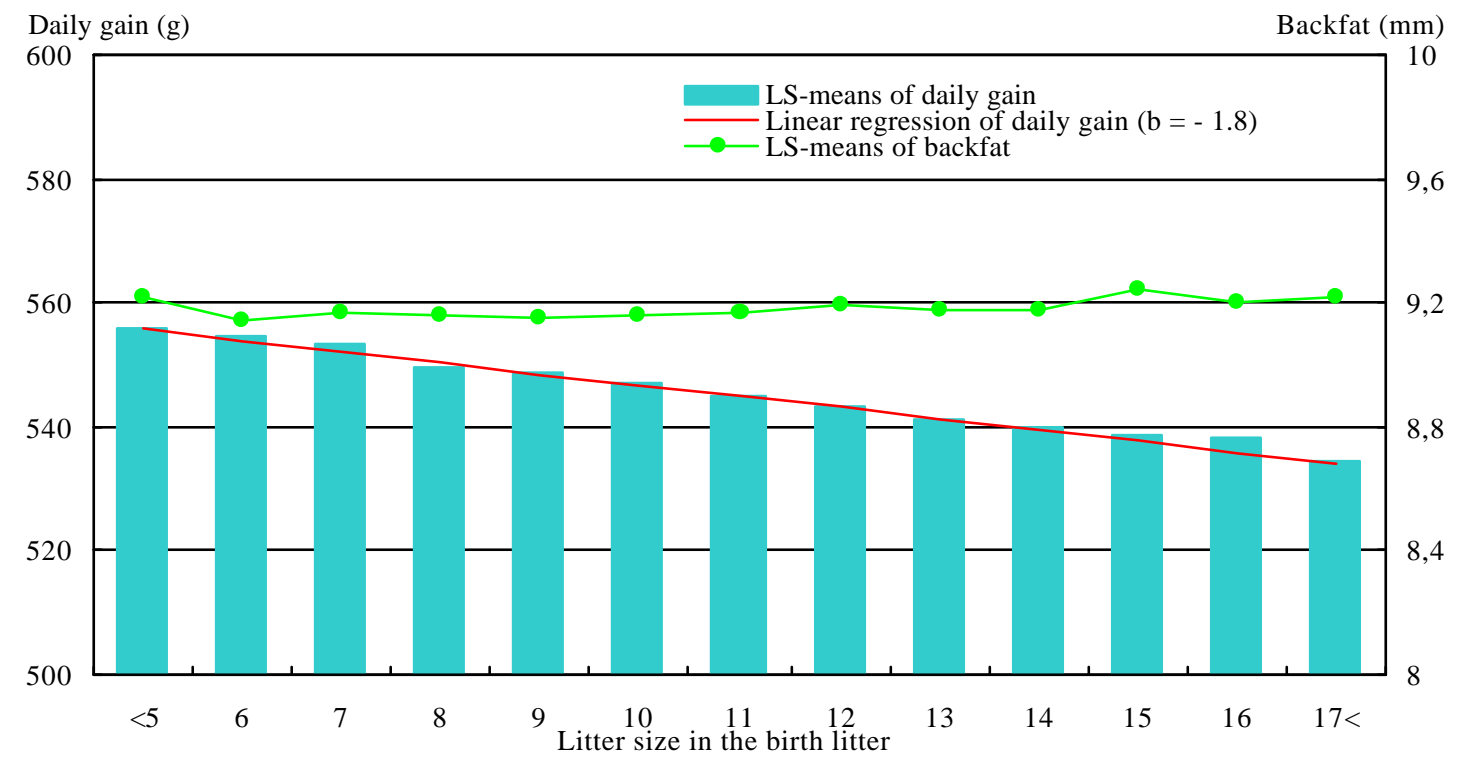

Figure 4.1. Effect of litter size in the birth litter on least square means of backfat and daily gain of young sows tested

The estimates of variance and covariance components are given in table 4.1. The estimated parameters for backfat thickness under the effect of litter size in the birth litter are not different between the four different models. The estimated parameters for daily gain are similar in models $1 \mathrm{a}$ and $1 \mathrm{c}$ and in models $1 \mathrm{~b}$ and $1 \mathrm{~d}$ respectively, but the differences between the four models are very small. 
Table 4.1. Estimates of variance and covariance components for backfat thickness and daily gain from the four different models

\begin{tabular}{llccccc}
\hline \multicolumn{1}{c}{ Model } & & $1 \mathrm{a}$ & $1 \mathrm{~b}$ & $1 \mathrm{c}$ & $1 \mathrm{~d}$ & Mean \\
\hline Backfat, & $\sigma_{\mathrm{a}}^{2}$ & 0.27 & 0.27 & 0.27 & 0.27 & 0.27 \\
$\mathrm{~mm}$ & $\sigma_{\mathrm{c}}^{2}$ & 0.16 & 0.16 & 0.16 & 0.16 & 0.16 \\
& $\sigma_{\mathrm{e}}^{2}$ & 0.70 & 0.70 & 0.70 & 0.70 & 0.70 \\
Daily gain, & $\sigma_{\mathrm{a}}^{2}$ & 656 & 644 & 656 & 643 & 650 \\
g/day & $\sigma_{\mathrm{c}}^{2}$ & 381 & 365 & 381 & 365 & 373 \\
& $\sigma_{\mathrm{e}}^{2}$ & 1,619 & 1,625 & 1,619 & 1,626 & 1,622 \\
Covariances & $\sigma_{\mathrm{aa}}$ & -0.62 & -0.50 & -0.63 & -0.50 & -0.56 \\
& $\sigma_{\mathrm{cc}}$ & 0.89 & 0.91 & 0.89 & 0.92 & 0.90 \\
& $\sigma_{\mathrm{ee}}$ & 2.27 & 2.22 & 2.27 & 2.24 & 2.25 \\
\hline
\end{tabular}

Table 4.2 presents estimates of the heritability $\left(h^{2}\right)$, proportion of variance due to common environment $\left(\mathrm{c}^{2}\right)$, the genetic correlation $\left(\mathrm{r}_{\mathrm{g}}\right)$ and also of the correlation between common environment $\left(r_{c}\right)$ and residual $\left(r_{e}\right)$ effect from the four different models. The estimates in table 4.2 show that the model to correct for litter size in the birth litter does not show any effect on heritabilities, common environmental effects for backfat thickness and daily gain or the correlations between both traits.

Table 4.2. Estimates of heritabilities, variance ratios and correlations for backfat thickness and daily gain from the four different models (standard error in brackets)

\begin{tabular}{lccccc}
\hline \multicolumn{1}{c}{ Model } & & 1a & $1 \mathrm{~b}$ & $1 \mathrm{c}$ & $1 \mathrm{~d}$ \\
\hline Backfat, & $\mathrm{h}^{2}$ & $0.24(0.01)$ & $0.24(0.01)$ & $0.24(0.01)$ & $0.24(0.01)$ \\
mm & $\mathrm{c}^{2}$ & $0.14(0.00)$ & $0.14(0.00)$ & $0.14(0.00)$ & $0.14(0.00)$ \\
Daily gain, & $\mathrm{h}^{2}$ & $0.25(0.01)$ & $0.24(0.01)$ & $0.25(0.01)$ & $0.24(0.01)$ \\
g/day & $\mathrm{c}^{2}$ & $0.14(0.00)$ & $0.14(0.00)$ & $0.14(0.00)$ & $0.14(0.00)$ \\
Correlations & $\mathrm{r}_{\mathrm{g}}$ & $-0.05(0.03)$ & $-0.04(0.03)$ & $-0.05(0.03)$ & $-0.04(0.03)$ \\
Backfat:Daily gain & $\mathrm{r}_{\mathrm{c}}$ & $0.12(0.01)$ & $0.12(0.01)$ & $0.12(0.01)$ & $0.12(0.01)$ \\
& $\mathrm{r}_{\mathrm{e}}$ & $0.07(0.01)$ & $0.07(0.01)$ & $0.07(0.01)$ & $0.07(0.01)$ \\
\hline
\end{tabular}


The breeding values for backfat thickness and daily gain are estimated using the mean values of estimated variance and covariance components with four different models (table 4.1). The correlations between the estimated breeding values for backfat thickness and daily gain from the four models are very high with values above 0.99 . The differences between estimated breeding values for daily gain between the four models are shown in table 4.3. The table shows that the differences between the models including litter size in the birth litter (models $1 \mathrm{~b}, 1 \mathrm{c}$ and $1 \mathrm{~d}$ ) are very small with a range between minimum and maximum difference of only 2 grams. The differences between model 1a and all other models show a much higher range of about 14 grams.

Table 4.3. Differences in estimated breeding values for daily gain between models $(\mathbf{n}=85,664)$

\begin{tabular}{ccccc}
\hline Difference & SD & Min & Max & Range \\
\hline $\mathrm{EBV}_{1 \mathrm{a}}-\mathrm{EBV}_{1 \mathrm{~b}}$ & 1.37 & -5.10 & 8.52 & 13.61 \\
$\mathrm{EBV}_{1 \mathrm{a}}-\mathrm{EBV}_{1 \mathrm{c}}$ & 1.31 & -6.40 & 7.48 & 13.88 \\
$\mathrm{EBV}_{1 \mathrm{a}}-\mathrm{EBV}_{1 \mathrm{~d}}$ & 1.48 & -5.49 & 9.13 & 14.62 \\
$\mathrm{EBV}_{1 \mathrm{~b}}-\mathrm{EBV}_{1 \mathrm{c}}$ & 0.23 & -1.86 & -0.18 & 1.67 \\
$\mathrm{EBV}_{1 \mathrm{~b}}-\mathrm{EBV}_{1 \mathrm{~d}}$ & 0.13 & -0.39 & 0.61 & 1.01 \\
$\mathrm{EBV}_{1 \mathrm{c}}-\mathrm{EBV}_{1 \mathrm{~d}}$ & 0.28 & 0.19 & 2.19 & 2.00 \\
\hline
\end{tabular}




\section{2. Significance test for litter traits}

The significance tests for the four litter traits in the parities are given in the following table 4.4. The four litter traits are analysed separately for fixed effects. The fixed effects herd-year-season and service boar line for all parities, and age at first farrowing as a covariate for first parity and farrowing intervals for second and third parity are considered in the linear models respectively. Additionally herd-year-season, service boar line and parity as fixed effects are considered from first to third parities.

Herd-year-season is a highly significant effect for all litter traits in all parities. As a covariate, age at first farrowing for first parity and the farrowing interval between first and second parities for number of piglets born in total, number of piglets born alive and number of piglets weaned respectively are highly significant. Number of piglets born dead is significantly affected in first parity by age at first farrowing only.

Table 4.4. Significance of effects on the litter traits

\begin{tabular}{lccccccc}
\hline \multicolumn{1}{c}{ Trait } & Effect & $\begin{array}{l}\text { Herd- } \\
\text { year- } \\
\text { season }\end{array}$ & $\begin{array}{l}\text { Service } \\
\text { boar line }\end{array}$ & $\begin{array}{l}\text { Age at } \\
\text { first } \\
\text { farrowing }\end{array}$ & $\begin{array}{l}\text { Farrowing } \\
\text { interval } \\
12\end{array}$ & $\begin{array}{l}\text { Farrowing } \\
\text { interval } \\
23\end{array}$ & Parity \\
\hline $\begin{array}{l}\text { Number of } \\
\text { piglets } \\
\text { born in }\end{array}$ & 1 & $* * *$ & $\mathrm{~ns}$ & $* * *$ & - & - & - \\
total & 2 & $* * *$ & $\mathrm{~ns}$ & - & $* * *$ & - & - \\
\hline $\begin{array}{l}\text { Number of } \\
\text { piglets }\end{array}$ & $1-3$ & $* * * *$ & $* * *$ & - & - & $*$ & - \\
born & 2 & $* * *$ & $\mathrm{~ns}$ & - & $* * *$ & - & - \\
alive & 3 & $* * *$ & $* * *$ & - & - & $*$ & - \\
\hline $\begin{array}{l}\text { Number of } \\
\text { piglets }\end{array}$ & $1-3$ & $* * *$ & $\mathrm{~ns}$ & - & - & - & $* * *$ \\
born \\
dead
\end{tabular}

Significance: $\mathrm{p} \leq 0.001=* * * ; \mathrm{p} \leq 0.01=* * ; \mathrm{p} \leq 0.05=* ; \mathrm{p}>0.05=\mathrm{ns}$, not used $=-$ 
Farrowing interval between second and third parities is a significant effect for number of piglets born in total, number of piglets born alive and number of piglets weaned as a covariate. It is not significant for number of piglets born dead.

Parity is a highly significant effect from first to third parities for all litter traits.

Service boar line in first and second parity is not significant for number of piglets born in total and number of piglets born alive, but in third parity it is highly significant for both traits. From first to third parities it is significant for number of piglets born in total but not for number of piglets born alive. Service boar line in first and third parity is not a significant effect for number of piglets born dead, but in second parity and from first to third parities it is significant. Service boar line is highly significant in first, in second parity and from first to third parities for number of piglets weaned, but not in third parity.

In these linear models herd-year-season and parity are significant effects for all traits when averaged over all parities. Age at first farrowing is significant for all litter traits in first parity.

The estimated regression coefficients for the covariates upon litter traits and their standard errors are given in table 4.5. The estimated regression coefficients for covariates age at first farrowing and farrowing interval 12 are similar but the one for farrowing interval 23 is considerably lower.

Table 4.5. Estimated regression coefficients for the covariates upon litter traits (standard error in brackets)

\begin{tabular}{lcccc}
\hline & NPBT & NPBA & NPBD & NPW \\
\hline Age at first farrowing & $.0087(.0007)$ & $.0078(.0007)$ & $.0009(.0003)$ & $.0053(.0006)$ \\
Farrowing interval 12 & $.0081(.0015)$ & $.0077(.0015)$ & $.0005(.0005)$ & $.0053(.0010)$ \\
Farrowing interval 23 & $.0056(.0022)$ & $.0053(.0021)$ & $.0003(.0008)$ & $.0031(.0015)$ \\
\hline
\end{tabular}


The least square means and standard errors of litter traits separately for the three parities are shown in table 4.6. Number of piglets born in total, born alive and weaned increase with parity. But number of piglets born dead does not differ with parity.

Table 4.6. Least square means of litter traits for the parity (standard error in brackets)

\begin{tabular}{lrccc}
\hline & NPBT & NPBA & NPBD & NPW \\
\hline 1. litter & $9.52(.021)$ & $8.95(.021)$ & $0.57(.008)$ & $8.48(.015)$ \\
2. litter & $10.16(.022)$ & $9.63(.022)$ & $0.53(.008)$ & $8.97(.016)$ \\
3. litter & $10.56(.024)$ & $9.97(.024)$ & $0.59(.009)$ & $9.09(.018)$ \\
\hline
\end{tabular}




\section{3. Estimation of variance components within each parity}

\section{3. 1. Analyses for the litter traits}

Estimates of variance and covariance components for litter traits (number of piglets born in total, number of piglets born alive, number of piglets born dead and number of piglets weaned) within each parity from several bivariate analyses are presented in table 4.7. Estimates of additive genetic variance for number of piglets born in total and born alive increase gradually from the first to the third parity. The additive genetic variances estimated for number of piglets born dead and weaned are lower in second parity as compared to first and third parities.

Table 4.7. Estimates of additive genetic variance $\left(1^{\text {st }}\right.$ line on the diagonal), residual variance $\left(2^{\text {nd }}\right.$ line on the diagonal), genetic covariance (above the diagonal) and residual covariance (below the diagonal) components for litter traits within parity using a multiple-trait animal model (model 2)

\begin{tabular}{|c|c|c|c|c|c|}
\hline Parity & Trait & NPBT & NPBA & NPBD & NPW \\
\hline \multirow{4}{*}{1} & NPBT & $\begin{array}{l}0.474 \\
5.732\end{array}$ & 0.424 & 0.051 & 0.189 \\
\hline & NPBA & 5.262 & $\begin{array}{l}0.394 \\
5.828\end{array}$ & 0.026 & 0.183 \\
\hline & NPBD & 0.470 & -0.564 & $\begin{array}{l}0.025 \\
1.034\end{array}$ & -0.002 \\
\hline & NPW & 2.485 & 2.885 & -0.385 & $\begin{array}{l}0.131 \\
3.393\end{array}$ \\
\hline \multirow{4}{*}{2} & NPBT & $\begin{array}{l}0.579 \\
7.073\end{array}$ & 0.526 & 0.057 & 0.161 \\
\hline & NPBA & 6.450 & $\begin{array}{l}0.479 \\
6.743\end{array}$ & 0.042 & 0.141 \\
\hline & NPBD & 0.619 & -0.289 & $\begin{array}{l}0.015 \\
0.909\end{array}$ & 0.015 \\
\hline & NPW & 2.763 & 3.030 & -0.254 & $\begin{array}{l}0.056 \\
3.298\end{array}$ \\
\hline \multirow{4}{*}{3} & NPBT & $\begin{array}{l}0.827 \\
6.566\end{array}$ & 0.765 & 0.062 & 0.257 \\
\hline & NPBA & 5.880 & $\begin{array}{l}0.734 \\
6.202\end{array}$ & 0.030 & 0.252 \\
\hline & NPBD & 0.687 & -0.321 & $\begin{array}{l}0.032 \\
1.008\end{array}$ & 0.004 \\
\hline & NPW & 2.452 & 2.735 & -0.260 & $\begin{array}{l}0.149 \\
3.113\end{array}$ \\
\hline
\end{tabular}

Estimates were obtained by bivariate analyses between litter traits.

Additive genetic and residual variances are the average of three bivariate estimates. 
Estimates of heritabilities, genetic and residual correlations are shown in table 4.8. Within each parity there is a decrease in heritability from number of piglets born in total to number of piglets born alive to number of piglets weaned to number of piglets born dead. Estimates of heritabilities for number of piglets born in total and number of piglets born alive within parity increase from first two parities to third parity, respectively. Estimates of heritability for number of piglets born dead and number of piglets weaned are lower than those for number of piglets born in total and number of piglets born alive within each parity.

Table 4.8. Estimates of heritabilities (on the diagonal), genetic (above the diagonal) and residual correlations (below the diagonal) for litter traits within parity using a multiple-trait animal model (model 2, standard error in brackets)

\begin{tabular}{cccccc}
\hline Parity & Trait & NPBT & NPBA & NPBD & NPW \\
\hline \multirow{2}{*}{1} & NPBT & $0.076(0.007)$ & $0.975(0.005)$ & $0.466(0.076)$ & $0.746(0.042)$ \\
& NPBA & $0.911(0.001)$ & $0.063(0.006)$ & $0.257(0.098)$ & $0.811(0.036)$ \\
& NPBD & $0.193(0.005)$ & $-0.230(0.005)$ & $0.024(0.004)$ & $-0.042(0.108)$ \\
& NPW & $0.564(0.004)$ & $0.646(0.003)$ & $-0.206(0.005)$ & $0.037(0.005)$ \\
\hline \multirow{2}{*}{2} & NPBT & $0.076(0.008)$ & $0.990(0.004)$ & $0.609(0.105)$ & $0.876(0.069)$ \\
& NPBA & $0.934(0.001)$ & $0.066(0.007)$ & $0.492(0.127)$ & $0.865(0.064)$ \\
& NPBD & $0.244(0.006)$ & $-0.117(0.006)$ & $0.016(0.004)$ & $0.517(0.200)$ \\
& NPW & $0.572(0.004)$ & $0.641(0.004)$ & $-0.147(0.006)$ & $0.017(0.005)$ \\
\hline \multirow{2}{*}{3} & NPBT & $0.112(0.010)$ & $0.981(0.004)$ & $0.379(0.083)$ & $0.733(0.047)$ \\
& NPBA & $0.921(0.001)$ & $0.106(0.010)$ & $0.192(0.099)$ & $0.766(0.043)$ \\
& NPBD & $0.267(0.006)$ & $-0.128(0.007)$ & $0.031(0.006)$ & $0.052(0.120)$ \\
& NPW & $0.542(0.006)$ & $0.620(0.005)$ & $-0.147(0.007)$ & $0.046(0.007)$ \\
\hline
\end{tabular}

Estimates were obtained by bivariate analyses between litter traits.

Heritabilities are the average of three bivariate estimates.

Estimates of the genetic correlation between number of piglets born in total and number of piglets born alive are close to one for all corresponding parities. Differences in these correlations between parities are very small. Genetic correlations between number of piglets born alive and number of piglets weaned are lower than between number of piglets born in total and number of piglets born alive for all parities. These 
correlations may be influenced by number of adopted piglets. Estimates of the genetic correlation between number of piglets born in total and number of piglets weaned are lower than estimates between number of piglets born alive and number of piglets weaned in first and third parity respectively. Low genetic correlations, which range from -0.042 to 0.466 , are estimated between number of piglets born dead and the other litter traits but in second parity moderate correlations are estimated from 0.492 to 0.609.

Estimates of residual correlation between number of piglets born in total and number of piglets born alive are high, but lower than genetic correlations in all corresponding parities. Estimates of residual correlations between number of piglets born in total or number of piglets born alive and number of piglets weaned are of moderate magnitude for all parities. Lower residual correlations were estimated between number of piglets born dead and the other litter traits for all parities.

\section{3. 2. Analyses for the calculated intervals}

For litter size and the calculated intervals variance and covariance components within second and third parity are estimated from multivariate analyses, separately (tables 4.9 and 4.10). For number of piglets born alive estimates of additive and residual variances are of the same magnitude in comparison to analyses for litter traits within parity (tables 4.7, 4.9 and 4.10). Variances estimated for farrowing intervals and weaning to conception intervals differ between second and third parity.

Estimates of heritabilities, genetic and residual correlations between litter size and intervals within second and third parity are presented in tables 4.11 and 4.12. Heritabilities estimated for number of piglets born alive are the same compared with the estimates for litter traits within parity (tables 4.8, 4.11 and 4.12). Estimates of heritabilities for farrowing intervals and weaning to conception interval decrease from second to third parity.

Estimates of genetic correlations between litter size and farrowing intervals or weaning to conception intervals are negative in second and third parity. The genetic correlation between farrowing interval 12 and weaning to conception interval 12 is close to one in second parity. Also in third parity the genetic correlation between farrowing interval 23 and weaning to conception interval 23 is close to one. These estimates prove that the farrowing interval and the weaning to conception interval in the same reproductive cycle are identical traits. Genetic correlations estimated between farrowing interval and weaning to conception interval in successive parity are of moderate magnitude. Estimates of residual correlations between farrowing interval and 
weaning to conception interval in the same cycle are high but a little bit lower than genetic correlations in two corresponding cycles. Estimates of residual correlations between litter size and intervals are low within each parity. These results may be influenced by management factors.

Table 4.9. Estimates of additive genetic variance $\left(1^{\text {st }}\right.$ line on the diagonal), residual variance $\left(2^{\text {nd }}\right.$ line on the diagonal), genetic covariance (above the diagonal) and residual covariance (below the diagonal) components for litter size and intervals within second parity using a multiple-trait animal model (model 3)

\begin{tabular}{ccccc}
\hline Trait & NPBA & FI12 & WCI12 & WCI23 \\
\hline NPBA & 0.481 & -0.936 & -0.928 & -0.404 \\
FI12 & 6.754 & 10.63 & 10.35 & 4.658 \\
& 2.181 & 168.7 & 10.51 & 5.137 \\
WCI12 & 2.317 & 155.4 & 155.8 & 3.072 \\
WCI23 & 0.368 & 4.831 & 4.803 & 98.56 \\
\hline
\end{tabular}

Estimates were obtained by multivariate analyses between reproductive traits.

Additive genetic and residual variances are the average of multivariate estimates.

Table 4.10. Estimates of additive genetic variance $\left(1^{\text {st }}\right.$ line on the diagonal), residual variance $\left(2^{\text {nd }}\right.$ line on the diagonal), genetic covariance (above the diagonal) and residual covariance (below the diagonal) components for litter size and intervals within third parity using a multiple-trait animal model (model 3)

\begin{tabular}{ccccc}
\hline Trait & NPBA & FI23 & WCI23 & WCI34 \\
\hline NPBA & 0.747 & -0.709 & -0.606 & -0.316 \\
FI23 & 6.200 & 3.634 & 3.338 & 1.186 \\
& 1.215 & 107.5 & 3.388 & 1.209 \\
WCI23 & 1.189 & 96.15 & 95.75 & 1.609 \\
WCI34 & -0.172 & 3.462 & 3.136 & 83.75 \\
\hline
\end{tabular}

Estimates were obtained by multivariate analyses between reproductive traits.

Additive genetic and residual variances are the average of multivariate estimates. 
Table 4.11. Estimates of heritabilities (on the diagonal), genetic (above the diagonal) and residual correlations (below the diagonal) for litter size and intervals within second parity using a multiple-trait animal model (model 3, standard error in brackets)

\begin{tabular}{ccccc}
\hline Trait & NPBA & FI12 & WCI12 & WCI23 \\
\hline NPBA & $0.067(0.007)$ & $-0.415(0.076)$ & $-0.413(0.037)$ & $-0.351(0.064)$ \\
FI12 & $0.065(0.007)$ & $0.060(0.008)$ & $0.972(0.005)$ & $0.775(0.090)$ \\
WCI12 & $0.071(0.006)$ & $0.959(0.001)$ & $0.063(0.008)$ & $0.861(0.084)$ \\
WCI23 & $0.014(0.006)$ & $0.038(0.007)$ & $0.039(0.007)$ & $0.030(0.006)$ \\
\hline
\end{tabular}

Estimates were obtained by multivariate analyses between reproductive traits.

Heritabilities are the average of multivariate estimates.

Table 4.12. Estimates of heritabilities (on the diagonal), genetic (above the diagonal) and residual correlations (below the diagonal) for litter size and intervals within third parity using a multiple-trait animal model (model 3, standard error in brackets)

\begin{tabular}{ccccc}
\hline Trait & NPBA & FI23 & WCI23 & WCI34 \\
\hline NPBA & $0.107(0.010)$ & $-0.424(0.089)$ & -0.381 & $-0.290(0.123)$ \\
FI23 & $0.047(0.008)$ & $0.033(0.007)$ & $0.954(0.013)$ & $0.503(0.187)$ \\
WCI23 & 0.049 & $0.947(0.001)$ & $0.034(0.007)$ & $0.516(0.181)$ \\
WCI34 & $-0.008(0.008)$ & $0.036(0.008)$ & $0.035(0.008)$ & $0.019(0.006)$ \\
\hline
\end{tabular}

Estimates were obtained by multivariate analyses between reproductive traits.

Heritabilities are the average of multivariate estimates. 


\section{4. Estimation of variance components between parities}

\section{4. 1. Analyses for the litter traits}

Estimated variance and covariance components for litter traits between parities from multivariate analyses are shown in table 4.13. Estimates of additive genetic variance for number of piglets born in total and number of piglets born alive increase gradually compared with the estimates within parity. The estimates of additive genetic variances obtained from two analyses for litter traits, within parity and between parities, are not exactly the same, but the increasing tendency from first to third parity is similar (tables 4.7 and 4.13).

Table 4.13. Estimates of additive genetic variance $\left(1^{\text {st }}\right.$ line on the diagonal), residual variance $\left(2^{\text {nd }}\right.$ line on the diagonal), genetic covariance (above the diagonal) and residual covariance (below the diagonal) components for litter traits between parities using a multiple-trait animal model (model 2)

\begin{tabular}{|c|c|c|c|c|}
\hline Traits & Parity & 1 & 2 & 3 \\
\hline \multirow{3}{*}{ NPBT } & 1 & $\begin{array}{l}0.503 \\
5.712\end{array}$ & 0.429 & 0.541 \\
\hline & 2 & 0.411 & $\begin{array}{l}0.647 \\
7.028\end{array}$ & 0.729 \\
\hline & 3 & 0.442 & 0.482 & $\begin{array}{l}0.925 \\
6.521\end{array}$ \\
\hline \multirow{3}{*}{ NPBA } & 1 & $\begin{array}{l}0.422 \\
5.809\end{array}$ & 0.377 & 0.463 \\
\hline & 2 & 0.342 & $\begin{array}{l}0.542 \\
6.701\end{array}$ & 0.626 \\
\hline & 3 & 0.409 & 0.430 & $\begin{array}{r}0.815 \\
6.165 \\
\end{array}$ \\
\hline \multirow{3}{*}{ NPBD } & 1 & $\begin{array}{l}0.028 \\
1.032\end{array}$ & 0.022 & 0.023 \\
\hline & 2 & 0.037 & $\begin{array}{l}0.019 \\
0.906\end{array}$ & 0.023 \\
\hline & 3 & 0.042 & 0.052 & $\begin{array}{l}0.038 \\
1.005\end{array}$ \\
\hline \multirow{3}{*}{ NPW } & 1 & $\begin{array}{l}0.141 \\
3.345\end{array}$ & 0.084 & 0.104 \\
\hline & 2 & 0.184 & $\begin{array}{l}0.063 \\
3.272\end{array}$ & 0.092 \\
\hline & 3 & 0.187 & 0.191 & $\begin{array}{l}0.167 \\
3.073\end{array}$ \\
\hline
\end{tabular}

Estimates were obtained by multivariate analyses between parities. 
Corresponding estimates of heritability for number of piglets born in total and number of piglets born alive increase from first to second to third parity respectively (table 4.14). Heritabilities estimated for number of piglets born dead and number of piglets weaned are lower than those for number of piglets born in total and number of piglets born alive. Particularly the estimated heritability for number of piglets weaned is very low in second parity.

Genetic and residual correlations between parities are also shown in table 4.14. Genetic correlations between different parities are generally high and consistent for all traits. High genetic correlations are found between adjacent parities for number of piglets born dead and number of piglets weaned. Generally, residual correlations between parities are larger for number of piglets born in total and number of piglets born alive than for number of piglets born dead and number of piglets weaned.

Table 4.14. Estimates of heritabilities (on the diagonal), genetic (above the diagonal) and residual correlations (below the diagonal) for litter traits between parity using a multiple-trait animal model (model 2, standard error in brackets)

\begin{tabular}{ccccc}
\hline Traits & Parity & 1 & 2 & 3 \\
\hline \multirow{2}{*}{ NPBT } & 1 & $0.081(0.006)$ & $0.752(0.032)$ & $0.793(0.038)$ \\
& 2 & $0.065(0.005)$ & $0.084(0.007)$ & $0.942(0.029)$ \\
& 3 & $0.072(0.007)$ & $0.071(0.007)$ & $0.124(0.007)$ \\
\hline NPBA & 1 & $0.068(0.006)$ & $0.788(0.033)$ & $0.790(0.028)$ \\
& 2 & $0.055(0.0050$ & $0.075(0.006)$ & $0.942(0.026)$ \\
& 3 & $0.068(0.007)$ & $0.067(0.007)$ & $0.117(0.007)$ \\
\hline NPBD & 1 & $0.026(0.004)$ & $0.975(0.040)$ & $0.705(0.104)$ \\
& 2 & $0.038(0.005)$ & $0.021(0.004)$ & $0.844(0.096)$ \\
& 3 & $0.041(0.007)$ & $0.054(0.007)$ & $0.036(0.008)$ \\
\hline NPW & 1 & $0.040(0.005)$ & $0.896(0.112)$ & $0.681(0.079)$ \\
& 2 & $0.056(0.005)$ & $0.019(0.004)$ & $0.896(0.048)$ \\
& 3 & $0.058(0.005)$ & $0.060(0.007)$ & $0.052(0.008)$ \\
\hline
\end{tabular}

Estimates were obtained by multivariate analyses between parities. 


\section{4. 2. Analyses for the calculated intervals}

Estimates of variance and covariance components for age at first farrowing and farrowing intervals from multivariate analyses are shown in table 4.15. Estimates of additive genetic and residual variances for farrowing intervals decrease from the first to the second cycle.

Estimates of variance and covariance components for weaning to conception intervals from multivariate analyses are shown in table 4.16. Additive genetic and residual variances estimated for weaning to conception intervals also decrease from the first to the successive cycles.

Table 4.15. Estimates of additive genetic variance ( $1^{\text {st }}$ line on the diagonal), residual variance $\left(2^{\text {nd }}\right.$ line on the diagonal), genetic covariance (above the diagonal) and residual covariance (below the diagonal) components for age at first farrowing and farrowing intervals using a multiple-trait animal model (model 3)

\begin{tabular}{cccc}
\hline Trait & AFF & FI12 & FI23 \\
\hline AFF & 102.6 & 12.21 & 6.968 \\
& 404.6 & 11.54 & 5.307 \\
FI12 & -12.77 & 168.1 & 4.204 \\
& & 2.964 & 107.1 \\
\hline
\end{tabular}

Table 4.16. Estimates of additive genetic variance $\left(1^{\text {st }}\right.$ line on the diagonal), residual variance $\left(2^{\text {nd }}\right.$ line on the diagonal), genetic covariance (above the diagonal) and residual covariance (below the diagonal) components for weaning to conception intervals using a multipletraits animal model (model 3)

\begin{tabular}{cccc}
\hline Trait & WCI12 & WCI23 & WCI34 \\
\hline \multirow{2}{*}{ WCI12 } & 12.39 & 6.638 & 3.414 \\
& 158.2 & 5.100 & 2.363 \\
WCI23 & 3.358 & 95.87 & 2.228 \\
& & 2.446 & 83.32 \\
\hline
\end{tabular}


Heritabilities estimated for intervals are shown in tables 4.17 and 4.18. Estimated heritability for age at first farrowing is larger than the other reproductive traits. Corresponding estimates of heritabilities for farrowing intervals decrease from the first to the second cycle. Estimates of heritability for weaning to conception intervals also decrease from the first to the third cycle. Low heritabilities estimated for intervals may be influenced by differences in the accuracy of estrus detection and prolonged intervals when a sow returned after an infertile mating.

Estimated genetic correlations between age at first farrowing and farrowing intervals are lower than estimates between farrowing intervals. Genetic correlations between adjacent intervals have moderate estimates. The estimated genetic correlation between weaning to conception interval 12 and weaning to conception interval 23 is moderate. All residual correlations between intervals have low estimates.

Table 4.17. Estimates of heritabilities (on the diagonal), genetic (above the diagonal) and residual correlations (below the diagonal) for age at first farrowing and farrowing intervals using a multiple-trait animal model (model 3, standard error in brackets)

\begin{tabular}{cccc}
\hline Trait & AFF & FI12 & FI23 \\
\hline AFF & $0.202(0.012)$ & $0.335(0.031)$ & $0.336(0.082)$ \\
FI12 & $-0.049(0.006)$ & $0.064(0.008)$ & $0.762(0.076)$ \\
FI23 & $-0.018(0.008)$ & $0.022(0.007)$ & $0.038(0.006)$ \\
\hline
\end{tabular}

Table 4.18. Estimates of heritabilities (on the diagonal), genetic (above the diagonal) and residual correlations (below the diagonal) for weaning to conception intervals using a multiple-trait animal model (model 3, standard error in brackets)

\begin{tabular}{cccc}
\hline Trait & WCI12 & WCI23 & WCI34 \\
\hline WCI12 & $0.073(0.008)$ & $0.835(0.051)$ & $0.650(0.115)$ \\
WCI23 & $0.027(0.007)$ & $0.051(0.007)$ & $0.701(0.100)$ \\
WCI34 & $0.037(0.007)$ & $0.023(0.007)$ & $0.026(0.006)$ \\
\hline
\end{tabular}




\section{5. Estimation of variance components using a repeatability model}

Variance and covariance components for litter traits from first to third parities estimated using a repeatability model are shown in table 4.19. Estimates of additive genetic variances for number of piglets born in total and number of piglets born alive are larger than estimates of number of piglets born dead and number of piglets weaned. Corresponding estimates of heritability are presented in table 4.20. Heritabilities gradually decrease from number of piglets born in total to number of piglets born alive to number of piglets weaned to number of piglets born dead. Estimates of repeatability for litter traits also decrease as estimates of heritability.

Table 4.19. Estimates of additive genetic $\left(V_{\mathrm{A}}\right)$, permanent environmental $\left(\mathrm{V}_{\mathrm{PE}}\right)$ and residual $\left(V_{E}\right)$ variance (on the diagonal) and covariance (above the diagonal) components for litter traits using a repeatability model (model 4)

\begin{tabular}{llllll}
\hline & Traits & NPBT & NPBA & NPBD & NPW \\
\hline \multirow{3}{*}{$\mathrm{V}_{\mathrm{A}}$} & NPBT & 0.562 & 0.551 & 0.052 & 0.191 \\
& NPBA & & 0.484 & 0.026 & 0.187 \\
& NPBD & & & 0.026 & 0.003 \\
& NPW & & & & 0.109 \\
\hline \multirow{3}{*}{$\mathrm{V}_{\mathrm{PE}}$} & NPBT & 0.408 & 0.369 & 0.039 & 0.156 \\
& NPBA & & 0.373 & -0.001 & 0.178 \\
& NPBD & & & 0.039 & -0.014 \\
& NPW & & & & 0.186 \\
\hline \multirow{3}{*}{$\mathrm{V}_{\mathrm{E}}$} & NPBT & 6.099 & 5.550 & 0.548 & 2.464 \\
& NPBA & & 5.956 & -0.407 & 2.767 \\
& NPBD & & & 0.955 & -0.296 \\
\hline
\end{tabular}

Estimates were obtained by bivariate analyses between litter traits.

Additive genetic and residual variances are the average of three bivariate estimates. 
Estimates of genetic, permanent environmental and residual correlations are presented in table 4.20. The genetic correlation estimated between number of piglets born in total and number of piglets born alive is very high, with a value of 0.997 , and the permanent environmental and residual correlations are also high, but slightly lower than the genetic correlation. The correlations estimated between number of piglets born in total and number of piglets weaned are estimated as being lower than between number of piglets born alive and number of piglets weaned. Genetic correlations between number of piglets born in total or number of piglets born alive and number of piglets weaned are larger than estimates for permanent environmental and residual correlations. The correlations estimated between number of piglets born dead and the other traits are estimated as being low, ranging from -0.171 to 0.427 .

Table 4.20. Estimates of heritabilities ( $1^{\text {st }}$ line on the diagonal $)$, repeatabilities $\left(2^{\text {nd }}\right.$ line on the diagonal), genetic ( $1^{\text {st }}$ line above the diagonal), permanent environmental $\left(2^{\text {nd }}\right.$ line above the diagonal) and residual correlations (below the diagonal) for litter traits using a repeatability animal model (model 4, standard error in brackets)

\begin{tabular}{ccccc}
\hline Traits & NPBT & NPBA & NPBD & NPW \\
\hline \multirow{2}{*}{ NPBT } & $0.080(0.004)$ & $0.997(0.003)$ & $0.427(0.045)$ & $0.768(0.026)$ \\
& 0.138 & $0.951(0.006)$ & $0.306(0.050)$ & $0.567(0.038)$ \\
NPBA & $0.921(0.001)$ & $0.071(0.004)$ & $0.227(0.057)$ & $0.811(0.020)$ \\
& & 0.125 & $-0.005(0.063)$ & $0.663(0.029)$ \\
NPBD & $0.227(0.003)$ & $-0.171(0.003)$ & $0.026(0.002)$ & $0.058(0.068)$ \\
& & & 0.059 & $-0.162(0.064)$ \\
NPW & $0.562(0.002)$ & $0.636(0.002)$ & $-0.171(0.004)$ & $0.032(0.003)$ \\
& & & & 0.085 \\
\hline
\end{tabular}

Estimates were obtained by bivariate analyses between litter traits.

Heritabilities and repeatabilities are the average of three bivariate estimates. 


\section{6. Estimation of variance components using the models including productive traits}

\section{6. 1. Litter traits, backfat and daily gain}

Estimates of variance and covariance components for litter size, backfat thickness and daily gain are presented in table 4.21. The estimates of additive genetic and residual variances obtained by several multivariate analyses for litter size, backfat thickness and daily gain are of the same magnitude and compare to estimates for number of piglets born alive within each parity (table 4.7).

Estimates of heritabilities and genetic, common environmental and residual correlations for litter size, backfat thickness and daily gain are shown in table 4.22. Estimates of heritability for number of piglets born alive are the same as the estimates for litter traits within each parity (tables 4.8, 4.11, 4.12 and 4.22).

Table 4.21. Estimates of additive genetic variance $\left(1^{\text {st }}\right.$ line on the diagonal), residual variance $\left(2^{\text {nd }}\right.$ line on the diagonal), genetic covariance (above the diagonal) and residual covariance (below the diagonal) components for litter traits, backfat thickness and daily gain using a multiple-trait animal model

\begin{tabular}{|c|c|c|c|c|c|}
\hline Traits & NPBA1 & NPBA2 & NPBA3 & $\begin{array}{l}\text { Backfat } \\
\text { thickness }\end{array}$ & Daily Gain \\
\hline NPBA1 & $\begin{array}{l}0.391 \\
5.831\end{array}$ & & & -0.010 & -1.139 \\
\hline NPBA2 & & $\begin{array}{l}0.480 \\
6.742\end{array}$ & & 0.021 & -0.358 \\
\hline NPBA3 & & & $\begin{array}{l}0.734 \\
6.202\end{array}$ & 0.006 & -1.788 \\
\hline $\begin{array}{l}\text { Backfat } \\
\text { thickness }\end{array}$ & 0.032 & 0.005 & 0.005 & $\begin{array}{l}0.183^{\mathrm{a}} \\
0.533^{\mathrm{a}} \\
0.191^{\mathrm{b}}\end{array}$ & $\begin{array}{l}1.378^{\mathrm{a}} \\
0.723^{\mathrm{b}}\end{array}$ \\
\hline Daily Gain & 3.325 & 2.129 & 1.962 & $3.529^{\mathrm{a}}$ & $\begin{array}{c}257.5 \\
1,063 \\
340.3\end{array}$ \\
\hline
\end{tabular}

Estimates were obtained by multivariate analyses between litter size and productive traits.

${ }^{a}$ Additive genetic, residual variances and covariances are the average of multivariate estimates.

${ }^{\mathrm{b}}$ Common environmental variance and covariance are the average of multivariate estimates. 
Table 4.22. Estimates of heritabilities (on the diagonal), genetic correlations (above the diagonal) and residual correlations (below the diagonal) for litter traits, backfat thickness and daily gain using a multipletrait animal model (standard error in brackets)

\begin{tabular}{|c|c|c|c|c|c|}
\hline Traits & NPBA1 & NPBA2 & NPBA3 & $\begin{array}{l}\text { Backfat } \\
\text { thickness }\end{array}$ & Daily Gain \\
\hline NPBA1 & $0.063(0.006)$ & & & $-0.038(0.028)$ & $-0.113(0.053)$ \\
\hline NPBA2 & & $0.067(0.007)$ & & $0.071(0.025)$ & $-0.032(0.020)$ \\
\hline NPBA3 & & & $0.106(0.009)$ & $0.017(0.039)$ & $-0.130(0.063)$ \\
\hline $\begin{array}{l}\text { Backfat } \\
\text { thickness }\end{array}$ & $0.018(0.007)$ & $0.002(0.007)$ & $0.003(0.009)$ & $\begin{array}{l}0.202(0.013)^{\mathrm{a}} \\
0.210(0.007)^{\mathrm{b}}\end{array}$ & $\begin{array}{l}0.201(0.026)^{\mathrm{a}} \\
0.090(0.020)^{\mathrm{b}}\end{array}$ \\
\hline Daily Gain & $0.042(0.007)$ & $0.025(0.008)$ & $0.024(0.010)$ & $0.149(0.012)^{\mathrm{a}}$ & $\begin{array}{l}0.155(0.013) \\
0.205(0.007)\end{array}$ \\
\hline
\end{tabular}

Estimates were obtained by multivariate analyses between litter traits and productive traits.

${ }^{a}$ Heritabilities, genetic and residual correlations are the average of three multivariate estimates.

${ }^{\mathrm{b}} \mathrm{c}^{2}$ and common environmental correlations are the average of multivariate estimates.

Genetic correlations between number of piglets born alive and productive traits, backfat thickness and daily gain are not consistent. The estimate of genetic correlation between number of piglets born alive in first parity and backfat thickness is slightly favourable but genetic correlations between number of piglets born alive in successive parities and backfat thickness are reversed in sign. Genetic correlations between number of piglets born alive and daily gain are negative and low. Residual correlations between backfat thickness or daily gain and number of piglets born alive are positive and low over all parities.

Estimated genetic, common environmental and residual correlations between backfat thickness and daily gain are unfavourable. 


\section{6. 2. Calculated intervals}

Estimates of variance and covariance components for intervals and productive traits from multivariate analyses are shown in tables 4.23 and 4.24 .

Table 4.23. Estimates of additive genetic $\left(1^{\text {st }}\right.$ line on the diagonal), residual variance $\left(2^{\text {nd }}\right.$ line on the diagonal), genetic covariance (above the diagonal) and residual covariance (below the diagonal) components for age at first farrowing, farrowing intervals, backfat thickness and daily gain using a multi ple-trait animal model

\begin{tabular}{cccccc}
\hline Traits & AFF & FI12 & F23 & $\begin{array}{c}\text { Backfat } \\
\text { thickness }\end{array}$ & Daily Gain \\
\hline AFF & 101.8 & & & 0.267 & -63.58 \\
& 405.1 & & & 0.001 & 3.962 \\
FI12 & & 10.29 & & & \\
FI23 & & & & 0.056 & 7.451 \\
Backfat & -0.688 & -0.328 & -0.070 & 0.107 .7 & \\
thickness & & & & $0.193^{\mathrm{b}}$ & $0.732^{\mathrm{b}}$ \\
Daily Gain & -65.31 & 13.19 & 3.778 & $3.554^{\mathrm{a}}$ & 1,063 \\
& & & & & 340.6 \\
\hline
\end{tabular}

Estimates were obtained by multivariate analyses between litter traits and productive traits.

${ }^{a}$ Additive genetic, residual variances and covariances are the average of multivariate estimates.

${ }^{\mathrm{b}}$ Common environmental variance and covariance are the average of multivariate estimates.

Estimates of heritabilities and genetic, common environmental and residual correlations for intervals, backfat thickness and daily gain are shown in tables 4.25 and 4.26 .

Estimates of heritability for age at first farrowing and farrowing intervals are similar to estimates in table 4.17. Heritabilities estimated for backfat thickness and daily gain are of the same magnitude as estimates in the analysis with litter size (table 4.22).

Genetic correlations between age at first farrowing and backfat thickness or daily gain are favourable. There is no genetic correlation between backfat thickness and farrowing interval in the first cycle, but in the second cycle these traits are positively (i.e. favourably) correlated. Genetic correlations between farrowing intervals and daily gain are positive (i.e. unfavourable). Residual correlations between age at first 
farrowing and backfat thickness or daily gain are negative and low. Estimates of residual correlations between farrowing intervals and backfat thickness are also negative and low. Between farrowing intervals and daily gain residual correlations are positive and low.

Table 4.24. Estimates of additive genetic ( $1^{\text {st }}$ line on the diagonal), residual variance $\left(2^{\text {nd }}\right.$ line on the diagonal), genetic covariance (above the diagonal) and residual variance (below the diagonal) components for weaning to conception intervals, backfat thickness and daily gain using a multi ple-trait animal model

\begin{tabular}{cccccc}
\hline Traits & WCI12 & WCI23 & WCI34 & $\begin{array}{c}\text { Backfat } \\
\text { thickness }\end{array}$ & Daily Gain \\
\hline WCI12 & 10.15 & & & 0.025 & 7.525 \\
& 155.8 & & & & \\
WCI23 & & 3.503 & & 0.034 & 10.23 \\
& & 95.36 & & & \\
WCI34 & & & & 0.005 & 2.026 \\
Backfat & -0.397 & -0.026 & 0.049 & $0.183^{\mathrm{a}}$ & $1.370^{\mathrm{a}}$ \\
Thickness & & & & $0.193^{\mathrm{a}}$ & $0.729^{\mathrm{b}}$ \\
& & & & & \\
Daily Gain & 10.02 & 0.766 & 1.347 & $3.532^{\mathrm{a}}$ & 1,064 \\
& & & & & 341.2 \\
\hline
\end{tabular}

Estimates were obtained by multivariate analyses between litter traits and productive traits.

${ }^{\text {a }}$ Additive genetic, residual variances and covariances are the average of multivariate estimates.

${ }^{\mathrm{b}}$ Common environmental variance and covariance are the average of multivariate estimates.

Estimates of heritability for weaning to conception intervals with productive traits are similar to estimates in table 4.18. Heritabilities estimated for backfat thickness and daily gain are of the same magnitude as estimates in the analysis with litter size (table 4.22).

Weaning to conception intervals correlate favourably with backfat thickness, but unfavourably with daily gain. Residual correlations between weaning to conception intervals and backfat thickness or daily gain are very low. 
Table 4.25. Estimates of heritabilities (on the diagonal), genetic correlations (above the diagonal) and residual correlations (below the diagonal) for age at first farrowing, farrowing intervals, backfat thickness and daily gain using a multiple-trait animal model (standard error in brackets)

\begin{tabular}{cccccc}
\hline Traits & AFF & FI12 & F23 & $\begin{array}{c}\text { Backfat } \\
\text { Thickness }\end{array}$ & Daily Gain \\
\hline AFF & $0.201(0.010)$ & & & $0.062(0.038)$ & $-0.387(0.054)$ \\
FI12 & & $0.057(0.008)$ & & $0.000(0.047)$ & $0.077(0.080)$ \\
FI23 & & & $0.031(0.006)$ & $0.071(0.046)$ & $0.252(0.103)$ \\
Backfat & $-0.047(0.009)$ & $-0.035(0.009)$ & $-0.009(0.008)$ & $0.201(0.012)^{\mathrm{a}}$ & $0.192(0.045)^{\mathrm{a}}$ \\
thickness & & & & $0.210(0.007)^{\mathrm{b}}$ & $0.091(0.022)^{\mathrm{b}}$ \\
Daily Gain & $-0.100(0.010)$ & $0.031(0.010)$ & $0.011(0.010)$ & $0.149(0.013)^{\mathrm{a}}$ & $0.155(0.013)$ \\
$0.205(0.007)$
\end{tabular}

Estimates were obtained by multivariate analyses between litter traits and productive traits.

${ }^{a}$ Heritabilities, genetic and residual correlations are the average of three multivariate estimates.

${ }^{b} c^{2}$ and common environmentalcorrelations are the average of multivariate estimates.

Table 4.26. Estimates of heritabilities (on the diagonal), genetic correlations (above the diagonal) and residual correlations (below the diagonal) for weaning to conception intervals, backfat thickness and daily gain using a multi ple-trait animal model (standard error in brackets)

\begin{tabular}{cccccc}
\hline Traits & WCI12 & WCI23 & WCI34 & $\begin{array}{c}\text { Backfat } \\
\text { Thickness }\end{array}$ & Daily Gain \\
\hline WCI12 & $0.061(0.008)$ & & & $0.019(0.040)$ & $0.148(0.077)$ \\
WCI23 & & $0.035(0.007)$ & & $0.042(0.054)$ & $0.345(0.101)$ \\
WCI34 & & & $0.023(0.007)$ & $0.009(0.125)$ & $0.090(0.062)$ \\
Backfat & $-0.044(0.009)$ & $-0.004(0.009)$ & $0.007(0.014)$ & $0.202(0.014) \mathrm{a}$ & $0.201(0.053)^{\mathrm{a}}$ \\
thickness & & & & $0.210(0.007)^{\mathrm{b}}$ & $0.091(0.026)^{\mathrm{b}}$ \\
Daily Gain & $0.025(0.010)$ & $0.002(0.010)$ & $0.005(0.007)$ & $0.148(0.013)^{\mathrm{a}}$ & $0.153(0.012)$ \\
$0.205(0.007)$
\end{tabular}

Estimates were obtained by multivariate analyses between litter traits and productive traits.

${ }^{a}$ Heritabilities, genetic and residual correlations are the average of three multivariate estimates.

${ }^{\mathrm{b}} \mathrm{c}^{2}$ and common environmentalcorrelations are the average of multivariate estimates. 


\section{Discussion}

\section{1. The effect of litter size in the birth litter on daily gain and backfat thickness of young sows tested}

This study estimated genetic parameters for reproductive traits along with growth rate and backfat thickness. The data used in this study include performance test and litter records of purebred sows in multiplier farms. At first, daily gain and backfat thickness of young sows tested were analysed together with number of piglets born in total of the litter in which the sow was born. Daily gain of young sows decreased with an increasing number of piglets in the birth litter in which the sow was born. There is a linear regression of litter size in the birth litter on daily gain of the young sows. For backfat thickness of young sows tested no visible trend upon litter size in the birth litter was found. Between different adjustments (models 1b, 1c and 1d) for litter size in the birth litter very small effects upon genetic parameters for daily gain and backfat thickness of young sows tested were found.

The breeding values for daily gain were estimated with four different models. From the results in table 4.3 it seems to be advantageous to consider the effect of litter size in the birth litter when estimating breeding values for daily gain of young sows tested. Although the correlations between breeding values from different models with and without litter size in the birth litter are high, for some animals differences in estimated breeding value of up to 10 grams are possible. The litter size in the birth litter can be included in the model as a fixed effect or as a covariate, but also a pre-adjustment with regression leads to the same results.

\section{2. The fixed effects upon reproductive traits}

Herd-year-season is a highly significant effect for the four reproductive traits in all parities. Herd-year effects or herd-year-season effects in animal breeding are often treated as fixed or random. Henderson (1975) showed that predictors of breeding values, derived ignoring selection, could be biased, if there is an association between breeding values and random herd-year subclasses. The bias disappears if the random herd-year effects are treated as fixed. He based his conclusions on a repeated sampling approach, where inferences were conditional on data structure and on the type of selection practised, and derived best linear unbiased predictors on the basis of this model. In other words, in Henderson's model, the pattern of missing data is fixed and 
variances are assumed known.

Service boar line has little or no influence on the litter size produced (Nelson and Robin, 1976; Koh et al., 1976; Buchanan and Johnson, 1984). However, individual boars within a breed can produce small litters if semen concentration and quality are so low that not all eggs are fertilised. This has not been reported as a breed trait but as an individual problem. Individual boars can also produce small litters if lethal genes are transmitted that result in death of a portion of the embryos. Therefore, studies of litter size in pigs can disregard the influence of the breed of the boar, particularly if females were mated by two different boars during the estrus that resulted in pregnancy (Clark and Leman, 1986b).

As a covariate, age at first farrowing and farrowing interval show significant effects on number of piglets born in total, number of piglets born alive and number of piglets weaned over all parities. The estimated regression coefficients for the covariates range from 0.003 to 0.087 in this study. Brandt (1984), Clark and Leman (1986a), Southwood and Kennedy (1991), Henne (1996) and Täubert (1998) estimated positive regressions for age at first farrowing and farrowing intervals, which ranged from 0.003 to 0.02 . For the effect of farrowing age litter size of first parity is corrected in some breeding evaluation programmes. A multivariate estimation of breeding values would be an alternative way of handling the relationship between age at first farrowing and litter size, and to achieve genetic progress in both traits (Rydhmer et al., 1995).

Parity is a highly significant effect from first to third parities for all litter traits in this study. A sow is placed in a parity category dependent on the number of litters she has farrowed. Consequently, parity is a categorical representation and not a precise measurement of chronological age. Therefore, the influence of parity on litter size should be considered cautiously, because of the wide range of possible sow ages within a parity (Clark and Leman, 1986a). In a review by Clark and Leman (1986a) a consistent finding is that litter size was smallest in the first parity, reached maximum size in parities 3, 4, 5 and then remained nearly constant or slowly declined as parity increased. Further investigation of late parity decline in litter size would be of great importance to the determination of a culling policy. The least square means for number of piglets born in total, born alive and weaned increase with parity in this study. But the parity did not affect the number of piglets born dead. 


\section{3. Estimates of variance components for reproductive traits}

Genetic improvement of any trait depends on the proportion of genetic variance that is additively inherited and on the amount of selection intensity. Estimates of variances and covariances have been used extensively in animal breeding. A large number of methods are now available, and the choice of one of them for a particular problem may well depend on what kind of objectives one has for the estimation of genetic parameters. With increasing emphasis upon multiple-trait evaluations, there is a need for general methods for estimation of covariances, and in particular when sequential culling is involved and consequently all traits are not observed on all animals (Henderson, 1986)

The estimates of heritability for number of piglets born in total and number of piglets born alive in the present study are between 0.063 and 0.112 using multiple-trait animal models. In this study heritabilities for the litter traits and the corresponding genetic correlations between litter traits are estimated by bivariate analyses within parity. The estimates of heritability for number of piglets born in total and number of piglets born alive are similar in first and second parity. The estimates of heritability for number of piglets born in total are higher than those for number of piglets born alive in all parities. Estimates of heritability for number of piglets born alive are in this study in general agreement with several reports that litter size in swine has a heritability of 0.10 (Ollivier, 1982; Haley et al., 1988). Evidence for this value has come from the analyses of Landrace and Large White or Yorkshire field data. More recent estimates of heritability for litter size at birth were in the range of 0.07 and 0.17 (Roehe and Kennedy, 1995; Rydhmer et al., 1995; Crump et al., 1997; Adamec and Johnson, 1997; Täubert, 1998; Bösch, 1999; Frey, 1999). These values were obtained using animal model that incorporated all the genetic relationships among individuals available. Estimates larger than 0.20 for litter size were reported by Jorgensen (1989) from paternal half-sib analyses and by Irgang et al. (1994) using an animal model.

Estimates of additive genetic and residual variance and heritability for litter traits between parities were obtained by multivariate analyses including records from first to third parities. This trivariate analysis diminishes a possible bias caused by culling of sows with low prolificacy. The estimates of additive genetic variance for these two traits increase with parity. But the estimates of residual variance for these two traits increase from first to second parity as well but decrease from second to third parity. Although increase of additive genetic variance of second parity for these two traits, estimates of heritability are similar in first and second parities because of the higher residual variances in second parity. However estimates of residual variance for these two traits in third parity are lower than those in second parity, estimates of heritability rise from second to third parity due to the increase of additive genetic variance. In this 
study the tendency of estimated additive genetic and residual variances and heritabilities for number of piglets born alive are in general agreement with several reports (Täubert, 1988; Bösch, 1999; Frey, 1999). In purebred sows although estimates of additive variance components for litter traits fluctuate from parity to parity, estimates of residual variance increase with parity. Estimates of total variance components for number of piglets born alive (6.231-7.243) have a more stable range than those for number of piglets born in total (6.215-7.675). These differences of variance components between number of piglets born in total and number of piglets born alive can be expected because of number of dead piglets.

The genetic parameters for litter traits from the two different analyses show a similar tendency. The increases of these estimates with parity were caused by a rise of the additive genetic variance component. The increased heritability with parity number is in accordance with the results from Irgang et al. (1994) for Large White and Landrace and Roehe and Kennedy (1995) and Täubert (1998). In contrast, no increase of heritability with parity was found by Haley et al. (1988) and Irgang et al. (1994) for Duroc sows. Selection has been suggested as a possible cause of low heritabilities in later parities (Irgang et al., 1994).

Based on the heritability for litter traits estimated in this study, it is expected that genetic improvement of reproductive performance could be made through selection. The negative relationship between litter size at birth and average daily gain (Kim et al., 2000), and between litter size and birth weight of piglets, complicates selection aimed at increasing litter size. The ultimate objective of breeding is of course to maximise the number of healthy piglets weaned. Number of piglets weaned is of greater commercial importance than litter size at birth (Haley et al., 1988). However, crossfostering is used under field conditions and litter size at weaning is difficult to standardise. Therefore the standardisation to prevent management factors such as crossfostering may be desirable in nucleus or multiplier herds to obtain more accurate genetic parameters for litter size at weaning.

Estimates of heritability for number of piglets weaned were in most cases low, they may have been underestimated because of crossfostering. The main causes of an increased number of pigs weaned per sow per year are husbandry changes, particularly earlier weaning, reduced weaning to conception intervals, and improved survival of piglets to weaning. There is no evidence that any of this change is due to genetic selection within lines or breeds, although there is a genetic contribution from breed substitution and from the use of hybrid sows. However, it is unclear whether the cause is genetic change or a consequence of environmental changes (Noguera and Legault, 1984). 
Estimates of heritability for daily gain, approximately between 0.15 and 0,25 , were similar or larger than those found in other studies of pigs tested on-farm (Merks, 1988; Hofer et al., 1992a) for which estimates are varying from 0.12 to 0.20 . The proportion of variation explained by common litter effects was lower than estimated in these studies. Estimates of additive genetic and residual variance for daily gain in Hofer et al. (1992a) were considerably smaller, and estimates of the litter variance were remarkably larger than this study. They explained a reason for overestimation of common litter effects at the expense of both genetic and residual variances. However, a higher estimate of heritability for daily gain $\left(h^{2}=0.35\right)$ was found by Tholen et al. (1996b). Estimates of heritability for backfat thickness were smaller in magnitude (approximately 0.2) than in other studies (Van Diepen and Kennedy, 1989; McKay, 1990; Rydhmer et al., 1995; Tholen et al., 1996b). Estimates of heritability for backfat thickness were similar to estimates in other studies (Merks, 1988). Estimates of variation explained by common litter effects are similar to other studies (Johansson and Kennedy, 1983; Merks, 1988; Van Diepen and Kennedy, 1989; Hofer et al., 1992).

The other reproductive problems facing pig breeders are a high rate of sows failing to recycle after farrowing and a prolonged interval between weaning and estrus. Because the date of first estrus after weaning is not recorded in sow management programmes of multiplier farms in the field, the interval from weaning to conception (successful mating), that includes interval from weaning to estrus is used instead in this study.

Estimates of heritabilities for weaning to conception intervals after the first, second and third farrowing in this study are within the range from 0.023 to 0.073 (tables 4.11 , $4.12,4.18$ and 4.26). These values are lower than those reported for the interval from direct analyses of the interval between weaning and estrus, ranging from 0.22 to 0.44 (Fahmy et al., 1979; ten Napel, 1995b), and similar to those reported for farrowing interval (Johansson and Kennedy, 1983; Maurer et al., 1985; Rydhmer et al., 1995).

Estimates of heritabilities for farrowing intervals are from 0.031 to 0.064 (tables 4.11 , $4.12,4.17$ and 4.25). Other estimates are within the range 0.04 to 0.22 as reported by Haley et al. (1988), by Adamec and Johnson (1997) and by Johansson and Kennedy (1985) for Landrace sows $\left(h^{2}=0.06 \pm 0.03\right)$ and Yorkshire sows $\left(h^{2}=0.09 \pm 0.05\right)$. Estimates of 0.17 by Johansson (1981) and 0.08 by Rydhmer et al. (1995) were, however, higher than those in this study.

Estimates of heritability for farrowing intervals are slightly less than for weaning to conception intervals within each cycle. But the differences are very small and negligible. Suckling period and gestation length contribute a small amount of variation to farrowing interval. Then genetic parameters for farrowing interval depend on those for weaning to conception interval within each reproductive cycle. Farrowing interval 
and weaning to conception interval in the same reproductive cycle could be treated as identical traits

Variations in these interval traits depend on the level of management. Apparently, additional variation due to returns to estrus after non-successful matings has only a small genetic basis. Whether genetic variation in the interval traits are observed depends on the level of management, less variation is observed in more extreme (favourable or unfavourable) environments (ten Napel et al., 1995a). Although farms were supposed to have the same management procedures, environments were slightly different across farms with respect to construction of buildings and stocking density. For this reason the interval traits were analysed carefully using the accurate model. Furthermore, sows in nucleus breeding herds not in estrus within 2 to 4 weeks after weaning are commonly culled. Both this culling practice and treatment with hormones in commercial herds yield a truncated distribution and cause additional variation between estimates. Consequently, estimates of parameters for weaning to conception interval are difficult to interpret and may be of very limited value. It is clear that genetic parameters are desired, which have a general value for a range of breeds and environments.

In a review, ten Napel et al. (1995a) hypothesised that genetic selection for increased daily gain, decreased backfat depth, increased litter size at birth, or increased litter weight at weaning may impair normal resumption of cyclic activity after weaning, in particular after weaning the first litter. Because the estimates of heritability for the interval traits are low, and because of the low genetic correlations with the productive traits, genetic selection for increased daily gain and decreased backfat is expected to have only a negligible effect on the interval traits. To study effects of selection for improved production on the interval traits in an alternative way, ten Napel et al. (1997) estimated differences in average estimated breeding values for the traits under selection between sows with normal and prolonged intervals. In terms of this method, the above hypothesis may be true when sows with a prolonged interval have on average a more favourable estimated breeding value in the traits selected for, than sows with a normal interval.

Greater improvements in interval traits were expected as a result of manipulating environmental factors of sow performance than from genetic solutions (Fahmy et al., 1979). The reduction of average weaning to conception interval will be achieved by decreasing the incidence of prolonged intervals, rather than by changing the mean duration of normal or prolonged intervals (ten Napel et al., 1995). 


\section{4. Genetic correlations among reproductive traits}

Estimates of genetic correlation between number of piglets born in total and number of piglets born alive within each parity are high and their estimates of heritabilitiy are similar within each parity (table 4.8), so selection for number of piglets born in total or number of piglets born alive will result in a similar response of each trait. However, selection for number of piglets born in total always has the risk of increasing number of piglets born dead. Also, estimates of heritability for number of piglets weaned are substantially lower than those for number of piglets born in total and number of piglets born alive, and their genetic correlations were of moderate magnitude only within each parity. These correlations may be influenced by crossfostering. Therefore, selection for number of piglets weaned is very difficult under the field conditions of crossfostering in multiplier farms.

In this study, genetic correlations between parities for each litter trait were in the range of 0.681 to 0.975 (table 4.14) and in agreement with literature averages reported by Haley et al. (1988) for the first three parities. Alfonso et al. (1997) reported that genetic correlations estimated under bivariate analyses were close to one from the first five parities for number of piglets born in total and born alive. For number of piglets born in total and number of piglets born alive the estimates of genetic correlation between first and successive two parities were from 0.75 to 0.79 . The correlations between second and third parities were 0.94 for both litter traits. The correlation between adjacent parities for number of piglets born dead and number of piglets weaned are over 0.84 . The moderate correlations between first and successive two parities for number of piglets born in total or number of piglets born alive may be influenced by intensive culling of sows for poor prolificacy and by environmental factors. With multivariate analysis methods there are possibilities to discover effects ignored in simpler models. The pairwise analysis of parities may have the advantage that estimates can be obtained without the restriction that the whole genetic variancecovariance matrix be positive definite (Roehe and Kennedy, 1995). The multivariate analysis diminishes possible bias, but complications arose with computational limits when attempts were made to analyse all four litter traits simultaneously. In addition to that, multivariate analysis is not affected by selection but it is not always successful, which is in agreement with Spilke and Groeneveld (1994). The use of a multivariate analysis for litter size is not clearly justified. The main reason is that the results obtained under a multivariate model are not reliable enough and those obtained under bivariate models are not sufficient to recommend a multiple-trait animal model with parities treated as different traits (Alfonso et al., 1997).

If genetic correlations between parities are low, then litters from different parities should be treated as different traits (Ollivier, 1982), and other forms of genetic 
evaluation, such as multiple-trait animal models, must be used to estimate breeding values. These models also allow, separate monitoring of the genetic progress within each parity. Genetic correlations between parities are sufficiently high that the repeatability model could be used for estimation of breeding values of sows in multiplier farms; it will be efficient in improving litter size over all parities. There are significant deviations from conditions in which the repeatability and multiple-trait models are equivalent models, as summarised by Henderson (1988). Firstly, the genetic correlations between parities should be one for the repeatability model. Secondly, the genetic variances of parities should be equal for the repeatability model. In this study the genetic variances for litter traits between parities were different, but the proportion of the estimated variance also increased from the first over second to third parities. Thirdly, the residual variances and covariances should be equal for assuming the repeatability model. In this study the residual variance is substantially lower in first parity but residual correlations between adjacent parities are similar and between first and third parities. In this case, although ratios of variance between additive and residual effects for each parity are slightly different, a nearly unique ratio for all parities could be assumed from the estimates of parameters using the repeatability model.

The repeatability model assumes that the litter size in different parities are repeated measurements of same trait, but it has been also suggested that the genetic background of litter size could be different for each parity, especially when comparing first versus the rest of parities (Vangen, 1986; Haley et al., 1988). However, in this case genetic correlations should be estimated accurately because multivariate models are more sensitive to parameter estimate errors than univariate models, particularly when heritabilities are low (Van der Werf et al., 1992). The possibility of this method would be the inclusion of all available information on traits and relatives in the evaluation process, resulting in higher accuracy of predictions and lower dependency on the effects of selection. Because the heritability of reproductive traits is relatively low and these traits cannot be observed in boars which are also candidates for selection.

In this study estimates of genetic parameters for litter traits using a repeatability model are similar to the estimates of multiple-trait models within parity. Alfonso et al. (1997) reported heritability of 0.06 and 0.07 for number of piglets born in total and of 0.05 and 0.06 for piglets born alive from the first five parities using a repeatability model. They gave the same repeatabilities for number of piglets born in total and born alive ranged from 0.13-0.15 as in this study. Frey (1999) estimated a slightly higher heritability ( 0.09 and 0.10$)$ and repeatability $(0.17$ and 0.18$)$ for number of piglets born alive than those in this study. The repeatability expresses the proportion of the variance of single measurements that is due to permanent differences between individuals, both genetic and environmental. It allows the separate estimation of the component due to 
the special environment as a proportion of the total (Falconer, 1989). It could be seen that the estimates of repeatability set an upper limit to the estimates of heritability for the litter traits of the three parities. The estimated genetic correlations between litter traits are also similar degree of multiple-trait model within parity and in the repeatability model.

Estimates of genetic correlations between farrowing intervals and number of piglets born alive with second and third parities are -0.415 and -0.425 respectively. Estimates of genetic correlations between number of piglets born alive and weaning to conception interval within parities are -0.413 and -0.381 , and estimates of genetic correlations between number of piglets born alive and consecutive weaning to conception intervals within parities are -0.351 and -0.290 . All estimates are negative but favourable. Adamec and Johnson (1995) reported an unfavourable correlation between litter size and weaning to conception interval, but the estimate was smaller $\left(\mathrm{r}_{\mathrm{g}}\right.$ $=0.08$ ) than in this study. Fahmy et al. (1979) and ten Napel et al (1995b) reported inconsistent relationships between weaning to estrus interval and litter size. Maurer et al. (1985) found the relationship to be non-linear. The farrowing intervals show small or no correlations with other productive and reproductive traits.

\section{5. Genetic correlations between reproductive and productive traits}

Genetic correlations between number of piglets born alive and productive traits, backfat thickness and daily gain are not consistent. Tholen et al. (1996b) found inconsistent correlation across their two herds. The inconsistency of genetic correlations between reproductive and productive traits are found in several literature sources (Johansson and Kennedy, 1983; Cleveland et al., 1988; McKay, 1990; Rydhmer et al., 1995). There are only small correlations between reproductive and productive traits.

Genetic correlations between farrowing intervals and backfat thickness are zero and slightly positive. Genetic correlation between weaning to conception interval and backfat thickness are favourable. Genetic correlations between the intervals and daily gain are unfavourable. These antagonistic relationships are explained in the review of ten Napel et al.(1995a). Firstly, genetic selection for minimal backfat is partially selection of animals with a low voluntary feed intake, at least during growth. Sows from these lines may have reduced lactational feed capacity, which causes severe losses in body weight during lactation, and subsequently a prolonged interval between weaning to estrus. Secondly, it has been suggested that young sows of genetically improved lines of lean pigs have low body fat reserves at parturition, and therefore 
reach detrimental depletion earlier than older sows.

\section{6. Conclusions}

For estimation of breeding values of dam line populations litter size in the birth litter can be included as a fixed effect or as a covariate in the model to estimate genetic parameters for daily gain. Another option with the same result is a pre-adjustment of daily gain to litter size in the birth litter.

The correlation between number of piglets born in total and number of piglets born alive is high. So selection for number of piglets born in total or number of piglets born alive will result in similar response of each trait. However, selection for number of piglets born in total has always the risk of increasing number of piglets born dead.

Genetic correlations between different parities are generally high and consistent for all litter traits. There is a small difference between the multiple-trait animal model and the repeatability model to estimate genetic parameters for litter traits.

Genetic correlations between number of piglets born alive and the calculated intervals are unfavourable but low. The genetic correlation between farrowing interval and weaning to conception interval within a cycle is high. Genetic correlations for the calculated intervals between different cycles are generally moderate. There are only small correlations between productive and reproductive traits, small or no correlated responses in intervals are therefore expected from selection for other productive and reproductive traits.

Estimates obtained in this study are likely more accurate than earlier estimates because of the use of restricted maximum likelihood under a multiple-trait animal model that accounts for selection between parities and the repeatability animal model. Even with the repeatability model a highly correlated response in all parities will be achieved. 


\section{Summary}

Reproductive performance is one of the important components of sow productivity, and is recognised as a key factor affecting the efficiency and economy of the pig industry. In particular, this leads to optimisation of the capacity of multiplier farms in crossbreeding programmes. Economic value of reproductive performance is expected to increase in the future. So, in order to combine both productive and reproductive performances of sows optimally in selection programmes, accurate estimates of variance and covariance components for all traits measured are necessary. The objectives of this study were to estimate genetic parameters for reproductive performance along with growth and backfat measures of sows, to use them for constructing optimised selection criteria for dam line sows and boars, and to develop practical procedures for breeding value estimation and selection of sows and boars in dam lines.

The data used in this study include performance test and litter records from purebred sows in multiplier farms of the Bundeshybridzuchtprogramm (BHZP). The production traits concerned are average daily gain and average backfat thickness of young sows tested. The reproductive traits set in place with parity and breeds are litter traits and calculated intervals.

The estimates of heritabilities and common environmental effects under consideration of the effect of litter size in the birth litter do not show any differences for backfat thickness and daily gain or the correlations between both traits. But it seems to be advantageous to consider the effect of litter size in the birth litter when estimating breeding values for daily gain, although the correlations between breeding values from models with and without litter size in the birth litter are high, for some animals differences of up to 10 grams in breeding value for daily gain are possible. The litter size in the birth litter can be included in the model as a fixed effect or as a covariate, but also a pre-adjustment with regression leads to the same result.

Genetic correlations between number of piglets born in total and number of piglets born alive are close to one for all corresponding parities. Differences in these correlations between parities are very small. Genetic correlations between number of piglets born in total or born alive and number of piglets weaned are lower than between number of piglets born in total and number of piglets born alive for all parities. These correlations may be influenced by crossfostering of piglets. Corresponding estimates of heritability for number of piglets born in total and number of piglets born alive increase from first over second to third parities. Heritabilities 
estimated for number of piglets born dead and number of piglets weaned are lower than those for number of piglets born in total and number of piglets born alive.

Genetic correlations between different parities are generally high and consistent for all litter traits. Variance and covariance components for litter traits from first to third parities are also estimated using a repeatability model. Heritabilities gradually decrease from number of piglets born in total to number of piglets born alive to number of piglets weaned to number of piglets born dead. Repeatabilities also decrease as heritabilities. The genetic correlation estimated between number of piglets born in total and number of piglets born alive is very high, with a value of 0.997 , and the permanent environmental and residual correlations are also high, but slightly lower than the genetic correlation.

Estimates of genetic correlations between litter size and intervals are negative. The genetic correlations between farrowing interval and weaning to conception interval are close to one in the same cycles. These estimates prove that farrowing interval and weaning to conception interval in the same parity could be treated as identical traits. Genetic correlations that estimated between farrowing interval and weaning to conception interval in successive parities are of moderate magnitude.

Correlations between age at first farrowing and backfat thickness or daily gain are favourable. There is no genetic correlation between backfat thickness and farrowing interval in the first cycle, but in the second cycle these traits are positively (i.e. favourably) correlated. Correlations between farrowing intervals and daily gain are unfavourable. Weaning to conception intervals correlate favourably with backfat thickness, but unfavourably with daily gain. Residual correlations between weaning to conception intervals and backfat thickness or daily gain are very low. Small or no correlated responses in intervals from selection for other productive and reproductive traits are expected.

Estimates obtained in this study are likely to be more accurate than earlier estimates because of the use of restricted maximum likelihood under a multiple-trait animal model that accounts for selection between parities. Even with the repeatability model, a highly correlated response in all parities will be achieved. 


\section{Zusammenfassung}

Die Reproduktionsleistung ist einer der wichtigen Bestandteile der Sauenproduktivität und ist als ein Schlüsselfaktor anerkannt, der die Effizienz und Wirtschaftlichkeit der Schweineindustrie beeinflusst. Besonders führt dies dazu, die Kapazität von Vermehrungsbetrieben in Kreuzungsprogrammen zu optimieren. Es wird erwartet, dass der ökonomische Wert der Reproduktionsleistung zukünftig zunimmt. Um sowohl Produktions- als auch Reproduktionsleistung von Sauen optimal in Selektionsprogrammen zu kombinieren, sind genaue Schätzungen von Varianz- und Kovarianzkomponenten für alle gemessenen Merkmale notwendig.

Die bei dieser Studie verwendeten Datenmaterialen enthielten Leistungsprüfungen und Wurfmeldungen von Reinzuchtsauen aus Vermehrungsbetrieben des Bundeshybridzuchtprogramms (BHZP). Die untersuchten Produktionsmerkmale sind tägliche Zunahme und Speckdicke getesteter Jungsauen. Die Reproduktionsmerkmale sind Wurfgröße, Zwischen-wurfzeit und das Intervall vom Absetzen bis zur erfolgreichen Belegung.

Die geschätzten Heritabilitäten und die gemeinsamen Umwelteffekte unter Berücksichtigung der Größe des Geburtswufes zeigen keine Unterschiede für Speckdicke und tägliche Zunahme wie die Korrelationen zwischen beiden Merkmalen. Die Wurfgröße kann in das Modell als ein fixer Effekt oder als eine Kovariable einbezogen werden, aber auch eine Vorkorrektur mit einer Regression für tägliche Zunahme führt zu denselben Ergebnissen.

Genetische Korrelationen zwischen der Anzahl total geborener Ferkel und der Anzahl lebend geborener Ferkel sind nahe bei eins für alle entsprechenden Würfe. Unterschiede zwischen diesen Korrelationen zwischen den Würfen sind sehr klein. Genetische Korrelationen zwischen der Anzahl total geborener oder der Anzahl lebend geborener Ferkel mit der Anzahl abgesetzter Ferkel sind niedriger als zwischen der Anzahl total geborener Ferkel und der Anzahl lebend geborener Ferkel für alle Würfe. Diese Korrelationen können von der Anzahl der zugesetzten Ferkel beeinflusst werden. Die Heritabilität für die Anzahl total geborener Ferkel und die Anzahl lebend geborener Ferkel steigt vom ersten bis zum dritten Wurf. Heritabilitäten für die Anzahl tot geborener Ferkel und die Anzahl abgesetzter Ferkel sind niedriger als die Heritabilitäten für die Anzahl total geborener Ferkel und die Anzahl lebend geborener Ferkel. 
Genetische Korrelationen zwischen verschiedenen Würfen sind allgemein hoch und einheitlich für alle Merkmale der Wurfgröße. Varianz- und Kovarianz-komponenten für die Merkmale der Wurfgröße vom ersten bis zum dritten Wurf wurden auch mit einem Wiederholbarkeitsmodell geschätzt. Die höchsten Heritabilitäten und Wiederholbarkeiten wurden für die Anzahl total geborener Ferkel geschätzt, gefolgt von der Anzahl lebend geborener Ferkel, der Anzahl abgesetzter Ferkel und der Anzahl tot geborener Ferkel. Die geschätzte genetische Korrelation zwischen der Anzahl total geborener Ferkel und der Anzahl lebend geborener Ferkel mit einem Wert von 0,997 liegt auf hohem Niveau. Die Korrelation zwischen den permanenten Umwelteffekten und die Korrelation zwischen den Resteffekten ist ebenfalls hoch, aber leicht niedriger als die genetische Korrelation.

Die genetischen Korrelationen zwischen der Wurfgröße und der Zwischenwurfzeit sowie der Wurfgröße und dem Intervall vom Absetzen bis zur erfolgreichen Belegung sind negativ. Die genetische Korrelation zwischen der Zwischenwurfzeit und dem Intervall vom Absetzen bis zur erfolgreichen Belegung ist nahe bei eins innerhalb eines Zyklus. Die geschätzten genetischen Korrelationen zeigen, dass die Zwischenwurfzeit und das Intervall vom Absetzen bis zur erfolgreichen Belegung im gleichen Zyklus als identische Merkmale behandelt werden können. Genetische Korrelationen zwischen der Zwischenwurfzeit und dem Intervall vom Absetzen bis zur erfolgreichen Belegung im darauffolgenden Zyklus sind von untergeordneter Bedeutung.

Korrelationen zwischen Erstferkelalter und Speckdicke oder der täglichen Zunahme sind günstig. Es gibt keine genetische Korrelation zwischen Speckdicke und der Zwischenwurfzeit im ersten Zyklus, aber im zweiten Zyklus sind diese Merkmale positiv (d.h. vorteilhaft) korreliert. Korrelationen zwischen der Zwischenwurfzeit und täglichen Zunahme sind ungünstig. Das Intervall vom Absetzen bis zur erfolgreichen Belegung korreliert vorteilhaft mit der Speckdicke, aber ungünstig mit der täglichen Zunahme. Die Korrelationen der Resteffekte zwischen dem Intervall vom Absetzen bis zur erfolgreichen Belegung und der Speckdicke oder der täglichen Zunahme sind sehr niedrig. Die Größenordnung der Korrelationen zwischen Produktions- und Reproduktionsmerkmalen liegt allgemein auf niedrigem Niveau. Es ist nur geringer Zuchtfortschritt in den Produktions- und Reproduktionsmerkmalen zu erwarten, wenn auf Zwischenwurfzeit oder das Intervall vom Absetzen bis zur erfolgreichen Belegung selektiert wird.

Die in einem Mehrmerkmalsmodell ermittelten Parameter mit korrekter Berücksichtigung der Selektion zwischen verschiedenen Würfen sind wahrscheinlich aussagekräftiger als die in früheren Arbeiten geschätzten Werte. Auch durch Anwendung eines Wiederholbarkeitsmodells wird ein hoch korrelierter Erfolg in allen Würfen erreicht. 


\section{References}

Adamec, V., and R. K. Johnson. 1997.

Genetic analysis of rebreeding intervals, litter traits, and production traits in sows of the National Czech nucleus. Livest. Prod. Sci. 48: 13-22.

Alfonso, L., J. L. Noguera, D. Babot, and J. Estany. 1997.

Estimates of genetic parameters for litter size at different parities in pigs. Livest. Prod. Sci. 47:149-156.

Bereskin, B. 1984.

A genetic analysis of sow productivity traits. J. Anim. Sci. 59:1149-1163.

Boylan, W. J., W. E. Rempel, and R. E. Comstock. 1961.

Heritability of litter size in swine. J. Anim. Sci. 20:566-568.

Bösch, M. 1999.

Die Selektion auf Wurfgröße beim Schwein unter besonderer Berücksichtigung der genetischen Beziehung zwischen Reinzucht- und Kreuzungsleistung. Dissertation Kiel.

Brandt, H. 1984.

Konstruktion optimaler Selektionskriterien für Sauenvermehrungsbetriebe mit eigener Bestandsremontierung. Dissertation Göttingen.

Brandt, H., H.-J. Kim, and P. Glodek. 1998.

Ansätze eines Stichprobentests für Fruchtbarkeit aus Sauenplanerdaten. Züchtungskunde. 70:362-371.

Brandt, H., and R. Wörner. 1995.

New field testing system for AI-boars. Archiv für Tierzucht. 38:299-304.

Buchanan, D. S., and R. K. Johnson. 1984.

Reproductive performance for four breeds of swine: crossbred females and purebred and crossbred boars. J. Anim. Sci. 59:948-956.

Clark, L. K., and A. D. Leman. 1986a.

Factors that influence litter size in pigs: Part1. Pig News Info. 7:303-308. 
Clark, L. K., and A. D. Leman. $1986 b$.

Factors that influence litter size in pigs: Part2. Pig News Info. 7:431-437.

Cleveland, E. R., R. K. Johnson, and P. J. Cunningham. 1988.

Correlated responses of carcass and reproductive traits to selection for rate of lean growth in swine. J. Anim. Sci. 66:1371-1377.

Crump, R. E., C. S. Haley, R. Thompson, and J. Mercer. 1997.

Individual animal model estimates of genetic parameters for reproduction traits of Landrace pigs performance tested in a commercial nucleus herd. Anim. Sci. 65:285290.

Edwards, R. L., and I. T. Omtvedt. 1971.

Genetic analysis of a swine control population. II. Estimation of population parameters. J. Anim. Sci. 32:185-190.

Estany. J., and D. Sorensen. 1995.

Estimation of genetic parameters for litter size in Danish Landrace and Yorkshire pigs. $60: 315-324$.

Falconer, D. S: 1989.

Introduction to quantitative genetics. Longman Scientific and Technical, Essex, England.

Farmy, M. H., W. B. Holtmann, and R. D. Baker. 1979.

Failure to recycle after weaning, and weaning to oestrus interval in crossbred sows. Anim. Prod. 29:193-202.

Ferguson, P. W., W. R. Harvey and K. M: Irvin. 1985.

Genetic, phenotypic and environmental relationships between sow body weight and sow productivity traits. J. Anim. Sci. 60:375-384.

Ferraz, J. B. S., and R. K. Johnson. 1993.

Animal model estimation of genetic parameters and response to selection for litter size and weight, growth, and backfat in closed seedstock populations of Large White and Landrace swine. J. Anim. Sci. 71:850-858.

Frey, M. 1999.

Zuchtwertschätzung für Reproduktionsmerkmale beim Schwein. Dissertation ETH Zürich. 
Glodek, P. 1999.

Actual problems and tendencies of development in pig breeding. Landbauforschung Völkenrode, Sonderheft. 193:43-52.

Groeneveld, E. 1990.

PEST User's manual.

Groeneveld, E. 1998.

VCE4 User's guide and reference manual Version 1.2.

Gu, Y., C. S. Haley, and R Thompson. 1989.

Estimates of genetic and phenotypic parameters of litter traits from closed lines of pigs. Anim. Prod. 49:477-482.

Haley, C. S., E. Avalos, and C. Smith. 1988.

Selection for litter size in the pig. Anim. Breed. Abst. 56:317-332.

Haley, C. S., and G. J. Lee. 1992.

Genetic factors contributing to variation in litter size in British Large White gilts. Livest. Prod. Sci. 30:99-113.

\section{Henderson, C. R. 1975.}

Best leaner unbiased estimation and prediction under a selection model. Biometrics. 31:423-447.

Henderson, C. R. 1986.

Recent developments in variance and covariance estimation. J. Anim. Sci. 63:208-216.

\section{Henderson, C. R. 1988.}

Theoretical basis and computational methods for a number of different animal models. J. Dairy Sci. 71(suppl.2):1-16.

Henderson, C. R., and R. L. Quaas. 1976.

Multiple trait evaluation using relatives' records. J. Anim. Sci. 43:1188-1197.

Henne, H. 1996.

Nutzung von Sauenplanerdaten in der Leistungsprüfung unter besonderer Berücksichtigung von Herkunftsvergleichen. Dissertation Göttingen. 
Henne, H., H. Brandt, and P. Glodek. 1997a.

Nutzung von Sauenplanerdaten in der Leistungsprüfung. 1. Mitteilung: Datenqualität und Nutzungsmöchlichkeiten in der Zuchtwertschätzung auf Fruchtbarkeit. Züchtungskunde. 69:196-207.

Henne, H., H. Brandt, and P. Glodek. 1997 b.

Nutzung von Sauenplanerdaten in der Leistungsprüfung. 2. Mitteilung: Nutzungsmöchlichkeiten bei Herkunftsprüfungen. Züchtungskunde. 69:279-293.

\section{Hofer, A., C. Hagger, and N. Künzi. 1992a.}

Genetic evaluation of on-farm tested pigs using an animal model. I. Estimation of variance components with restricted maximum likelihood. Livestock Prod. Sci. 30:6982.

\section{Hofer, A., C. Hagger, and N. Künzi. $1992 b$.}

Genetic evaluation of on-farm tested pigs using an animal model. II. Prediction of breeding values with a multiple trait model. Livestock Prod. Sci. 30:83-98.

Irgang, R., J. A. Favero, and B. W. Kennedy. 1994.

Genetic parameters for litter size of different parities in Duroc, Landrace, and Large White sows. J. Anim. Sci. 72:2237-2246.

\section{Johansson, K. 1981.}

Some notes concerning the genetic possibilities of improving sow fertility. Livest. Prod. Sci. 8:431-447.

Johansson, K., and B. W. Kennedy. 1983.

Genetic and phenotypic relationships of performance test measurements with fertility in Swedish Landrace and Yorkshire sows. Acta Agric. Scand. 33:195-199.

Johansson, K., and B. W. Kennedy. 1985.

Estimation of genetic parameters for reproductive traits in pigs. Acta Agric. Scand. 34:421-431.

\section{Jorgensen, J. N. 1989.}

The influence of maternal effects on litter size in pigs. Acta Agric. Scand. 39:421-429.

Kemp, B., and N. M. Soede. 1996.

Relationship weaning-to-estrus interval to timing of ovulation and fertilisation in sows. J. Anim. Sci. 74:944-949. 
Kaplon, M. J., M. F. Rothchild, P. J. Berger, and M. Healey. 1991.

Population parameter estimates for performance and reproductive traits in Polish Large White nucleus herds. J. Anim. Sci. 69:91-98.

Kim, H.-J., H. Brandt, H. Henne, and P. Glodek. 2000.

The effects of litter size at birth on parameters for backfat and daily gain. Vortragstagung der DGfZ/GfT. Kiel.

Koh, T. J., B. G. Crabo, H. L. Tsou, and E. F. Graham. 1976.

Fertility of liquid boar semen as influenced by breed and season. J. Anim. Sci. 42:138144.

Kuhlers, D. L., and S. B. Jungst. 1993.

Correlated responses in reproductive and carcass traits to selection for 200-day weight in Landrace pigs. J. Anim. Sci. 71:595-601.

Long, T. E., R. K. Johnson, and J. W. Keele. 1990.

Effects of errors in pedigree on three methods of estimating breeding value for litter size, backfat and average daily gain in swine. J. Anim. Sci. 68:4069-4078.

Maurer, R. R., J. J. Ford, and R. K. Christenson, 1985.

Interval to first postweaning estrus and causes for leaving the breeding herd in Large White, Landrace, Yorkshire and Cherster White females after three parities. J. Anim. Sci. 61:1327-1334.

McKay, R. M. 1990.

Responses to index selection for reduced backfat thickness and increased growth rate in swine. Can. J. Anim. Sci.70:973-977.

\section{Merks, J. W. M. 1988.}

Genotype $\times$ environment interactions in pig breeding programs. III. Environment effects and genetic parameters in on-farm test. Livest. Prod. Sci. 18:129-140.

Nelson, R. E., and O.W. Robinson, 1976.

Comparison of specific two- and three way crosses in swine. J. Anim. Sci. 42:11501157.

Noguera, J. L., and C. Legault. 1984.

Trends in productivity of sows during the last ten years in France. Pig News Info. 5:205-212. 
Ollivier, L. 1982.

Selection for prolificacy in the pig. Pig News Info. 3:383-388.

Revelle, T. J., and O. W. Robinson. 1973.

An explanation for the low heritability of litter size in swine. J. Anim. Sci. 37:668-675.

Roehe, R., and B. W. Kennedy. 1995.

Estimation of genetic parameters for litter size in Canadian Yorkshire and Landrace swine with each parity of farrowing treated as a different trait. J. Anim. Sci. 73:29592970.

Rydhmer, L., N. Lundeheim, and K. Johansson. 1995.

Genetic parameters for reproduction traits in sows and relations to performance-test measurements. J. Anim. Breed. Genet. 112:33-42.

Southwood, O. I., and B. W. Kennedy. 1990.

Estimation of direct and maternal genetic variance for litter size in Canadian Yorkshire and Landrace swine using an animal model. 68:1841-1847.

Southwood, O. I., and B. W. Kennedy. 1991.

Genetic and environmental trends for litter size in swine. J. Anim. Sci. 69:3177-3182.

Spilke, J., and E. Groeneveld. 1994.

Comparison of four multivariate REML (co)variance component estimation packages. In: Proc. $5^{\text {th }}$ World Congr. on Genetics Appl. Livestock Production, Guelph, Vol. XXII, pp. 11-14.

Strang, G. S., and J. W. B. King. 1970.

Litter productivity in Large White pigs. 2. Heritabiility and repeatability estimates. Anim. Prod. 12:235-243.

Strang, G. S., and C smith. 1979.

A note on the heritability of litter traits in pigs. Anim. Prod. 28:403-406.

\section{Täubert, H. 1998}

Schätzung von Varianz- und Kovarianzkomponenten für die Wurfgröße von Reinzucht- und Kreuzungssauen. Dissertation Göttingen.

ten Napel, J., B. Kemp, P. Luiting, and A. G. de Vries. 1995a.

A biological approach to examine genetic variation in weaning-to-oestrus interval in first-litter sows. Livest. Prod. Sci. 41:81-93. 
ten Napel, J., A. G. de Vries, G. A. J. Buiting, P Luiting, J. W. M. Merks, and E. W. Brascamp. 1995 b.

Genetics of the interval from weaning to estrus in first-litter sows: Distribution of data, direct response of selection, and heritability. J. Anim. Sci. 73:2193-2203.

ten Napel, J., and R. Johnson. 1997.

Genetic relationships among production traits and rebreeding performance. J. Anim. Sci.75:51-60.

ten Napel, J., T. H. E. Meuwissen, R. K. Johnson, and E. W. Brascamp. 1998.

Genetics of the interval from weaning to estrus in first-litter sows: Correlated response. J. Anim. Sci. 76:937-947.

The National Committee for Pig Breeding, Health and Production. 1997. Annual Report. Copenhagen, Denmark.

Tholen, E., K. Bunter, S. Hermesch, and H-U. Graser. 1996a.

Genetic Foundation of fitness and reproduction traits in Australian pig populations. I. Genetic parameter for weaning to conception interval, farrowing interval and stayability. Aust. J. Agric. Res. 47:1261-1274.

Tholen, E., K. Bunter, S. Hermesch, and H-U. Graser. 1996 b.

Genetic Foundation of fitness and reproduction traits in Australian pig populations. II. Relationships between weaning to conception interval, stayability and common reproduction and production traits. Aust. J. Agric. Res. 47:1275-1290.

Urban, W. E., Jr., C. E. Shelby, A. B. Chapman, J. A. Whatley, Jr., and V. A. Garwood. 1966.

Genetic and environmental aspects of litter size in swine. J. Anim. Sci. 25:1148-1153.

Van Diepen, T. A., and B. W. Kennedy. 1989.

Genetic correlations between test station and on-farm performance for growth rate and backfat in pigs. J. Anim. Sci. 67:1425-1431.

Van der Werf, J. H. J., J. A. M. van Arendonk, and A. G. De Vries. 1992.

Improving selection of pigs using correlated characters. In: Proc. $43^{\text {rd }}$ Annu. Meeting of European Assoc. for Animal Production, Madrid.

Vangen, O. 1981.

Problems and possibilities for selection for fecundity in multiparous species. Pig News Info. 3:257-263. 
Vangen, O. 1986.

Genetic control of reproduction in pigs: From parturition to puberty. In: Proc. $3^{\text {rd }}$ World Congr. on Genetics Appl. Livestock Production, Nebraska, Vol. XI, pp. 168179.

Young, L. D., R. A. Pumfrey, P. J. Cunningham, and D. R. Zimmerman. 1978.

Heritabilities and genetic and phenotypic correlations for prebreeding traits, reproductive traits and principal components. J. Anim. Sci. 46:937-949. 


\section{Acknowledgements}

I am deeply grateful to Prof. Dr. Peter Glodek, my "Doktorvater", for his profound guidance of my studies and assistance regarding many aspects of my life in Germany. I express my gratitude to Prof. Dr. Horst Brandt, my co-supervisor, for his critical comments from the outset to the conclusion of this thesis.

I am indebted to Dr. Hubert Henne at the Züchtungszentrale Deutsches Hybridschwein $\mathrm{GmbH}$ in Lüneburg for providing data for this study. Many thanks to all my colleagues at the Institute of Animal Breeding and Genetics for supporting my research.

I thank Burchhard Möllers for his active support in matters of computer and software, Sven König for a talk full of valuable suggestions and for smooth German in the summary, and Prof. Dr. Erich Bruns, Teresa Dohms, Eva Moors, Annette Wilke, Frieder Hamm, Dr. Worawut Chainetr and Dr. Sigurd Laube for the generous offering of discussion time.

Special thanks go to Jane Eggers and Sönke Eggers, best friends of my family, for reading the scribbles and making grammatical comments.

Many thanks to the Niedersächsisches Ministerium für Wissenschaft und Kultur for providing me with a scholarship in the context of the "Nachwuchswissenschaftler aus außereuropäischen Ländern nach Niedersachsen" programme.

I express my appreciation to my mother and my late father.

Last, but certainly not least, I thank my wife Sun-Young, who supported me with unlimited tolerance, understanding and devotion throughout this project. 



\section{Curriculum Vitae}

Name:

Born:

Family status :

School:

1973 - 1979 Elementary School in Seoul, Korea

1979 - 1985 Middle and High School in Seoul, Korea

\section{University:}

1985 - 1989 The Department of Animal Science, College of Agriculture, Korea University in Seoul, Korea

Bachelor of Agriculture

1989 - 1991 The Department of Animal Science, Graduate School, Korea University

Master of Agriculture

1991 - 1993 The Department of Animal Science, Graduate School, Korea University

Completed the Doctor Course Work

since November 1997 Doctor Course of Agricultural Sciences

at the Institute of Animal Breeding and Genetics,

Georg-August-University of Göttingen, Germany

\section{Military service:}

1993 - 1998 Replacement as Research Assistant at various Institutes

\section{Occupation:}

1992 - 1993 Civil Servant at the National Alpine Experimental Station, (Department of Animal Breeding)

Rural Development Administration

1993 - 1995 Research Assistant at the Institute of Natural Resources, Korea University

1995 - 1997 Research Assistant at the Daesang Co., Ltd.

1997 - 1998 Research Assistant at the Institute of Natural Resources, Korea University

1997 - $1998 \quad$ Research Training Fellow in the Exchange Programme between Korea and Germany in Göttingen, Financial support from KOSEF

1999 - $2001 \quad$ Fellowship recipient of the Niedersächsisches Ministerium für Wissenschaft und Kultur 